\title{
Health treatment cost, stillbirth, survival, and conformation of Viking Red-, Montbéliarde-, and Holstein-sired crossbred cows compared with pure Holstein cows during their first 3 lactations
}

A. R. Hazel,, ${ }^{*}$ B B. J. Heins, (1) and L. B. Hansen $(1)$

Department of Animal Science, University of Minnesota, St. Paul 55108

\begin{abstract}
Three generations of crossbreds from a 3-breed rotation of the Viking Red (VR), Montbéliarde (MO), and Holstein $(\mathrm{HO})$ breeds were compared with their $\mathrm{HO}$ herdmates in 7 commercial dairy herds in Minnesota. The designed study enrolled 3,550 HO females in 2008 to initiate crossbreeding and a control of pure $\mathrm{HO}$ herdmates within each herd. Service sires were highranking, proven AI bulls selected for high genetic merit within each of the VR, MO, and $\mathrm{HO}$ breeds. Cows in this study calved from 2010 to 2017 and collection of data ended on December 31, 2017. The first generation of cows consisted of $644 \mathrm{VR} \times \mathrm{HO}$ and $616 \mathrm{MO} \times \mathrm{HO}$ crossbreds and their 1,405 HO herdmates. The second generation had $615 \mathrm{VR} \times \mathrm{MO} / \mathrm{HO}$ and $568 \mathrm{MO} \times$ VR/HO crossbreds and their 1,462 HO herdmates. The third generation had 466 combined $\mathrm{HO} \times \mathrm{VR} / \mathrm{MO} / \mathrm{HO}$ and $\mathrm{HO} \times \mathrm{MO} / \mathrm{VR} / \mathrm{HO}$ crossbreds and their $736 \mathrm{HO}$ herdmates. Total health cost was the sum of veterinary treatment cost, pharmaceutical cost, and farm labor cost to treat 16 different health disorders. Conformation traits and body condition score were subjectively scored once during early lactation for each of the first 3 lactations of cows. Total health cost of the 2-breed crossbreds was significantly lower during first $(-23 \%)$, second $(-29 \%)$, and third $(-21 \%)$ lactation compared with their HO herdmates. For the 3-breed crossbreds, total health cost did not differ during first lactation but was $-26 \%$ lower during both second and third lactation compared with their HO herdmates. The stillbirth rate for calves born to 2-breed crossbred dams (4\%) was significantly lower compared with calves born to their $\mathrm{HO}$ herdmates (8\%) at first calving. Survival from first to third calving $(+9 \%)$ and first to fourth calving $(+11 \%)$ was significantly higher for the 2-breed crossbreds compared with their HO herdmates. Also, the 3-breed crossbreds had significantly higher survival
\end{abstract}

Received March 27, 2020.

Accepted June 22, 2020.

*Corresponding author: haze0025@umn.edu to third $(+11 \%)$ and fourth $(+19 \%)$ calving compared with their HO herdmates. Across each generation of crossbreeding, the crossbreds had uniformly shorter stature, less angularity, and less body depth compared with their respective $\mathrm{HO}$ herdmates. The crossbred cows also had significantly less udder clearance from the hock but significantly more rear teat width and longer teat length compared with their respective $\mathrm{HO}$ herdmates. Furthermore, the crossbred cows had higher body condition score compared with their HO herdmates during each of their first 3 lactations.

Key words: crossbreeding, total health cost, Montbéliarde, Viking Red

\section{INTRODUCTION}

Milk production is the largest source of income from cows for most dairy herds. However, the profit from cows is heavily influenced by costs related to fertility, health treatment, stillbirth (SB), mortality, and early culling. Therefore, dairy cattle selection has moved to a more comprehensive breeding goal in recent years that includes increased emphasis on robustness to varied environments (Rauw and Gomez-Raya, 2015) with particular emphasis on fertility, cow health, and longevity (Miglior et al., 2017). Various surveys (EggerDanner et al., 2015) have found dairy producers place a higher priority on genetic improvement of functional traits than on genetic improvement of milk production. Furthermore, the well-being of cows has increasing importance to consumers of dairy products globally (Oltenacu and Broom, 2010).

Aside from long-term crossbreeding in New Zealand, most developed countries of the world have only recently begun to grow their percentage of crossbred cows. During the last $40 \mathrm{yr}$, the Holstein (HO) breed has predominated globally because of the breed's successful selection for milk production. However, the emphasis on milk production of $\mathrm{HO}$ cows has contributed to impaired cow fertility, reduced cow health, increased SB rate, and shortened herd life over time (Sørensen et al., 2008; Egger-Danner et al., 2015; Dechow and Hansen, 
2017). Many studies have suggested crossbreeding of dairy cattle may improve immunity (Cartwright et al., 2012), lower the incidence of health disorders (Funk, 2006; Jönsson, 2015), and increase general robustness (Sørensen et al., 2008; Peric et al., 2013). In recent years, crossbreeding has experienced an international rise in popularity for commercial milk production because the fitness level of $\mathrm{HO}$ cows has eroded with both increased milk production (Koeck et al., 2014; Miglior et al., 2017) and higher inbreeding coefficients (Dechow and Hansen, 2017).

In the United States, the HO breed has experienced a rapid acceleration of the annual increase of inbreeding coefficient $(+0.42 \%)$ among females born during the most recent 3 yr (Council on Dairy Cattle Breeding, http://queries.uscdcb.com/eval/summary/inbrd.cfm). This explosive annual rate of increase of mean inbreeding coefficient of $\mathrm{HO}$ females will result in a reduction of allelic diversity that could dampen the potential for genetic improvement of $\mathrm{HO}$ cows on a long-term basis (Dickerson and Hazel, 1944; Doublet et al., 2019). The traits that first experience inbreeding depression in dairy cattle are typically fetal survival, SB, resistance to health disorders, and cow survival (Sørensen et al., 2008). Dairy producers may expect the most meaningful benefit from crossbreeding for these lowly heritable traits because inbreeding depression and heterosis are both due to the genetic effects of dominance and have essentially equal and opposite effects (Falconer and Mackay, 1996).

In addition to the effects of heterosis, the additive genetic effects provided by non-HO breeds in combination with $\mathrm{HO}$ in a crossbreeding rotation may provide additional benefit. In particular, the Viking Red (VR) and Montbéliarde (MO) breeds, which originate from the Nordic countries and France, respectively, are popular for crossbreeding. The Nordic countries have had meticulous data recording for health disorders and selected against health disorders for over $40 \mathrm{yr}$ (Parker Gaddis, 2014). The MO breed has a long-term history of selection for subjectively scored muscularity of cows (http://montbeliarde.org/objectifs-de-selection .html), and this selection has resulted in MO cows with increased body condition as well as improved fertility compared with HO cows (Balandraud et al., 2018). Increased body condition and improved fertility of dairy cattle are both associated with improved cow health. The VR and MO breeds have both been selected for production of milk solids concurrently with selection for fertility and health traits for many years and for longer than the HO breed in the United States (Colleau and Regaldo, 2001; Parker Gaddis, 2014). The VR and MO breeds may be well suited to complement the $\mathrm{HO}$ breed for rotational crossbreeding because the $\mathrm{HO}$ breed emphasized genetic improvement for higher milk production and improved udder conformation for many years before moving to more comprehensive selection goals in recent years that include the fertility and health of cows (VanRaden et al., 2018).

The objective of this study was to analyze phenotypes for health treatment cost, SB, survival, and conformation traits from the first 3 lactations of $\mathrm{VR} \times \mathrm{HO}$ and $\mathrm{MO} \times \mathrm{HO}$ 2-breed crossbreds and $\mathrm{VR} \times \mathrm{MO} / \mathrm{HO}$ and $\mathrm{MO} \times \mathrm{VR} / \mathrm{HO} 3$-breed crossbreds compared with their respective $\mathrm{HO}$ herdmates in a 10-yr designed study. Additionally, the third generation of HO-sired crossbred cows were compared with their HO herdmates during first lactation for the same traits. Fertility and 305-d production for the same cows and lactation numbers were previously reported by Hazel et al. (2020).

\section{MATERIALS AND METHODS}

\section{Experimental Design}

Description of Herds and Cows. A 10-yr, designed study was initiated from March to September of 2008 to compare phenotypes of cows resulting from the first 3 generations of a 3 -breed rotational crossbreeding with the phenotypes of their HO herdmates. A total of 7 herds located in Minnesota followed the experimental design initiated by the researchers for the 10-yr duration of the study. A thorough description of the herds and the experimental design was provided in Hazel et al. $(2017,2020)$. The cows in the 7 herds were housed in freestall confinement facilities and fed a TMR. The herds were high-ranking among Minnesota dairy herds for their level of production and overall management. Collectively, they had mean herd size of $982 \pm 203$ cows at the end of data collection in December 2017.

Each herd enrolled a minimum of $250 \mathrm{HO}$ foundation females to initiate the study that were mostly nulliparous heifers, first-lactation cows, or second-lactation cows. However, some herds enrolled considerably more foundation $\mathrm{HO}$ females than the minimum, and the total number enrolled was 3,550 HO foundation females across the 7 herds. Within each herd, heifers and cows were comingled without regard to breed type and were grouped only by age, stage of lactation, or reproductive status. Also, the dairy producers provided equal treatment to all breed groups for reproductive, health care, and culling protocols.

Mating Design and Sire Selection. Foundation HO females were assigned to be mated by AI to either VR or MO bulls for initiation of 3-breed rotational crossbreeding or by $\mathrm{AI}$ to $\mathrm{HO}$ bulls for continuous purebreeding (Figure 1). The foundation HO females were paired for mating based on age and sire for heifers 
or lactation number, sire, and projected 305-d matureequivalent milk production, which was adjusted for age at calving and stage of lactation of cows. Each herd was required to commit a minimum of 100 foundation HO females for crossbreeding and a minimum of 150 foundation $\mathrm{HO}$ females for purebreeding. Additional foundation heifers and cows were mated to the breed group (crossbred or HO) chosen by each dairy producer; therefore, across the 7 herds, $28 \%, 28 \%$, and $44 \%$ were mated by $\mathrm{AI}$ to $\mathrm{VR}, \mathrm{MO}$, and $\mathrm{HO}$ bulls, respectively. The 2-breed crossbreds from the first generation were mated to the third breed and their HO herdmates were mated by AI to HO bulls. Subsequently, all secondgeneration heifers and cows were mated by $\mathrm{AI}$ to $\mathrm{HO}$ bulls to create HO-sired crossbred females and their HO herdmates. The mating design including the foundation $\mathrm{HO}$ cows and the 3 generations of crossbreds and their HO herdmates is shown in Figure 1. Two genetic advisors employed by Minnesota Select Sires Co-op Inc. (St. Cloud, MN) individually mated all heifers and cows. The crossbreds and HO cows were correctively mated for conformation to improve the worst faults of cows in their daughters, and heifers were correctively mated based on conformation of their dams when possible. Inbreeding protection was provided for the AI mating of the HO herdmates with HO bulls.

Bulls from the VR, MO, and HO breeds were chosen by the dairy producers with consultation from the 2 genetic advisors, and only unsexed semen from proven AI bulls was mated to both heifers and cows. Creative Genetics of California (Oakdale, CA) imported the semen of VR and MO bulls to the United States, and the bulls ranked highly among those available for the Nordic Total Merit Index (http://nordicebv.info/ntm -nordic-total-merit-2) or the French ISU index (http:// montbeliarde.org/en-428.html), which are the national selection indices for the VR and MO breeds, respectively. Semen from proven HO bulls was from Select Sires Inc. (Plain City, OH), and the 7 dairy producers were asked to select bulls from the top $10 \%$ of bulls available for the Net Merit index (VanRaden et al., 2018). A small number of inseminations did not conform to those prescribed in the study design, and progeny resulting from those inseminations were not included in the study.

Initial Data Editing. During the first generation, $13.7 \%$ of 2-breed crossbreds and their HO herdmates left the herds before first calving. Overall, $17.0 \%$ of 3 -breed crossbreds and their HO herdmates and $20.2 \%$ of HO-sired crossbreds and their HO herdmates either left the herds before first calving or had not yet calved by the time data collection ceased. A detailed description of numbers of heifers that exited the herds before first calving is available in Hazel et al. (2020).

Lactations of cows that commenced with abortion (days of gestation $<260 \mathrm{~d}$ ) were removed from the analyses of health treatment cost, SB, and conformation traits; however, lactations that commenced with abortion remained in the analysis of survival. Across generations, 59 crossbred and $61 \mathrm{HO}$ cows had first lactations that commenced with abortion, but the second and third lactations of those cows were potentially included for analysis if gestation length (GL) was $\geq 260$ d. Across generations, 65 crossbred and $52 \mathrm{HO}$ cows

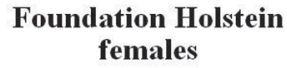

First generation (2-breed crossbreds and their HO herdmates)

Second generation
(3-breed crossbreds and (3-breed crossbreds and
their HO herdmates)

Third generation (HO-sired crossbreds and their HO herdmates)

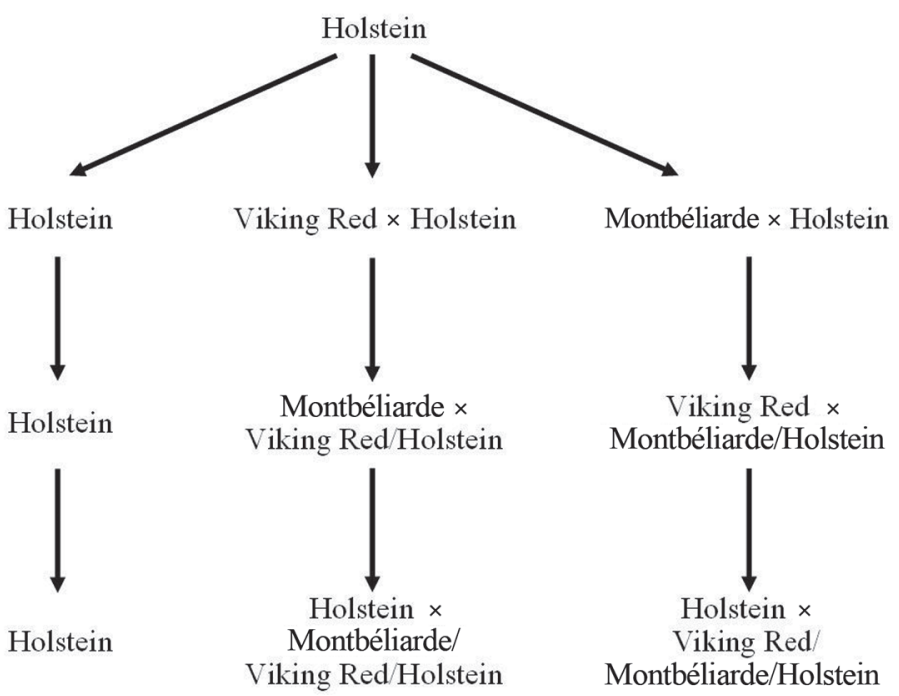

Figure 1. Mating design for the 3 generations of crossbred cows and their Holstein (HO) herdmates. 
Table 1. Total cost (US\$) assigned to types of health treatment

\begin{tabular}{llrrr}
\hline Category & Type of health treatment & $\begin{array}{c}\text { Veterinary } \\
\text { cost }^{2}\end{array}$ & $\begin{array}{c}\text { Labor } \\
\text { cost }^{3}\end{array}$ & Total \\
\hline MAST & Mastitis & 22 & 6 & 28 \\
& Mastitis diagnostic test & 8 & 3 & 11 \\
\multirow{2}{*}{ REPRO } & Infectious pododermatitis (hoof rot) & 52 & 9 & 61 \\
& All other hoof treatment & 6 & 9 & 15 \\
& Cystic ovaries & 14 & 2 & 16 \\
& Retained placenta & 75 & 5 & 80 \\
& Metritis & 112 & 5 & 117 \\
META & Miscellaneous reproduction (severe) & 335 & 36 & 371 \\
& Miscellaneous reproduction (other) & 6 & 7 & 13 \\
& Milk fever & 21 & 17 & 38 \\
\multirow{2}{*}{ MISC } & Displaced abomasum & 256 & 19 & 275 \\
& Ketosis & 24 & 9 & 33 \\
& Digestive & 34 & 10 & 44 \\
& Respiratory & 67 & 10 & 77 \\
& Injury & 3 & 23 & 26 \\
& Other & 25 & 6 & 31 \\
\hline
\end{tabular}

${ }^{1} \mathrm{MAST}=$ mastitis; LAME $=$ lameness REPRO $=$ reproduction $;$ META $=$ metabolic; and MISC $=$ miscellaneous.

${ }^{2}$ Veterinary costs were obtained from the veterinary clinics that provided service for the 7 herds.

${ }^{3}$ Fixed labor cost $(\$ 18 / \mathrm{h})$ across the 7 herds.

had second lactations that commenced with abortion, and 52 crossbred and $34 \mathrm{HO}$ cows had third lactations that commenced with abortion.

\section{Trait Descriptions}

Health Treatment Cost. Health treatments were recorded in the 7 herds by the dairy producers or their employees using Dairy Comp 305 (Valley Agricultural Software, Tulare, CA). Monthly backups from Dairy Comp 305 were obtained directly from the 7 herds, and health treatments were downloaded and systematically assigned across herds to 16 types of health treatments (Table 1). Researchers for this study had direct contact with the dairy producers or their employees to ensure correct assignment of the health treatments and remarks associated with health treatments for completeness of recording. The health treatments were partitioned into 5 categories: mastitis (MAST), reproduction (REPRO), lameness (LAME), metabolic (META), and miscellaneous (MISC). The specific types of health treatments that were assigned to the 5 categories are in Table 1. Mastitis diagnostic test treatments included both milk culture and California Mastitis Test (Immucell, Portland, ME). The "all other hoof treatment" category included dermatitis, foot ulcer, and other hoof treatments, but did not include the cost of routine hoof trimming. The "miscellaneous reproduction-severe" treatments included cesarean section, prolapse, and uterine torsion. The "miscellaneous reproduction-other" treatments included pyometra, abortion, adhesion, and all other reproduction treat- ments. Digestive treatments included clostridium, traumatic reticuloperitonitis, hemorrhagic bowel syndrome, peritonitis, twisted cecum, lack of appetite, and all other digestive treatments. Prophylactic health treatments that were routinely administered to all cows in a herd were not included, such as fresh cow treatments, vaccinations, or dry cow treatments.

The collection of cost (US\$) of health treatments was completed by Donnelly (2017) during February 2016 and was exclusive to the 7 herds in this study. Health treatment costs were based on interviews with the 7 dairy producers and their veterinarians. First, the veterinary service cost for each of the 16 types of health treatments was obtained from the veterinarians providing service to the 7 herds. Pharmaceutical costs were either obtained from veterinarians or an average catalog cost of pharmaceuticals from 5 veterinary service vendors that serve Minnesota. Therefore, veterinary cost (Table 1) included veterinarian labor, supplies, and pharmaceuticals used for health treatment. Second, the labor cost was obtained from interviews with the dairy producers or their employees. The time in minutes assigned to each health treatment included the time for owners or employees to constrain cows and administer the health treatment. The labor cost was the product of the fixed hourly wage $(\$ 18 / \mathrm{h})$ across the 7 herds and the average time in minutes reported by the dairy producers or their employees. Finally, veterinary cost and labor cost were summed for each type of treatment (Table 1).

For cows with repeated health treatments of the same type within a lactation, a new health treatment 
was designated daily for cows with multiple mastitis diagnostic tests, injuries, or other (MISC) treatments. A new health treatment was designated after $3 \mathrm{~d}$ between hoof treatments (on the same hoof); after $5 \mathrm{~d}$ between mastitis treatments (on the same quarter) as well as metritis, milk fever, ketosis, digestive, and respiratory treatments; and after $7 \mathrm{~d}$ between cystic ovary and "miscellaneous reproduction-other" treatments. Only one health treatment per lactation was designated for retained placenta, "miscellaneous reproduction-severe," and displaced abomasum. The quarter or hoof that was treated was provided for more than $90 \%$ of the health treatments for mastitis and lameness; therefore, the cost of health treatment was applied to each quarter or hoof independently, regardless of whether multiple quarters or hooves were treated on the same day.

The total health cost (THC) for each cow was the sum of all 16 types of health treatments and was initiated on the day of calving and continued across all days of lactation and the subsequent dry period. Lactations from calving to subsequent calving, culling, or death were variable in length. However, no edit was imposed for minimum length of lactation because a goal of the study was to include the health treatment cost of cows with health disorders that may have resulted in removal from the herd shortly after calving.

$S B$ and $G L$. The SB was recorded in a binary manner as either living or dead within $24 \mathrm{~h}$ of birth. The GL was the date of successful insemination subtracted from the date of calving. The SB, dates of insemination, and dates of calving were recorded by the dairy producers or their employees in Dairy Comp 305.

Survival. The survival traits were based on dates of calving or disposal recorded in Dairy Comp 305. Survival of cows was a binary trait of survived (1) or not (0) to a subsequent calving either within a fixed interval of time or to a subsequent calving. The percentage of cows that calved again within 14 mo and the percentage of cows that calved again within 17 mo of the previous calving were the number of cows that subsequently calved within 14 and 17 mo, respectively, divided by the number of cows that calved initially for each lactation number. The 14- and 17-mo intervals were chosen to represent calving intervals that were acceptable versus lengthy. Death loss was a binary trait analyzed separately within each lactation number and cows completed lactations with death or euthanasia on the farm (1) or live culling or survival to a subsequent lactation (0). Therefore, the death loss percentage was the number of cows that died divided by the total number of cows that calved for each lactation number. Survival to subsequent calving was determined cumulatively across lactations of cows without regard to the length of calving interval and data were recorded as calved (1) or did not calve (0) for a second, third, or fourth lactation. Survival to third and fourth calving spanned the 2 or 3 lactations, respectively, from the time of first calving.

Conformation and Body Condition. The 2 genetic advisors collected and provided all data for conformation traits and BCS of cows. Conformation traits and BCS were scored once from 2 to 150 DIM during each of the first 3 lactations for cows calving from 2009 to 2014. During 2015, conformation traits, but not BCS, were scored once per lactation for the first 3 lactations. During 2016 and 2017, only cows in first lactation were scored for conformation traits and not for BCS. The scoring of conformation traits during first lactation was a routine service provided by the genetic advisors to facilitate corrective matings for cows. However, the conformation traits and BCS for multiparous cows was only collected for this study.

The conformation traits analyzed included stature (STA), which was height at the withers, angularity (ANG), body depth (BD), foot angle (FA), udder clearance (UC), which was relative to hock, rear teat width (RTW), and teat length (TL) of the front teats. Conformation traits were scored from 1 to 9 in increments of 1 , and scores were assigned independent of age or stage of lactation (Select Sires Inc., Plain City, $\mathrm{OH}$ ). The scale used to score each of the conformation traits is in Table 2. Scoring for all traits was identical across breed groups. All scores were assigned subjectively; however, measurement goals were provided for STA, FA, UC, and TL. For all conformation traits, the intermediate score (5) was a biological midpoint and was not necessarily a mean score for the trait. The BCS was subjectively scored on a 5-point scale in increments of 0.25 with $1=$ thin and $5=$ obese (Ferguson et al., 1994).

\section{Final Editing and Analysis}

Each of the 3 generations of crossbred cows and their respective HO herdmates were analyzed separately for each trait because the design of the study did not allow for substantial overlap of generations within lactation number. The 10-yr duration of the study allowed for analysis of the first 3 lactations for the 2-breed and 3 -breed crossbreds and their respective $\mathrm{HO}$ herdmates. However, the HO-sired crossbreds and their HO herdmates commenced first calving in September 2014; therefore, very few of those cows had an opportunity to complete multiparous lactations before data collection ceased on December 31, 2017.

Health Treatment Cost. The 2-breed crossbreds and their HO herdmates for analysis of health treatment cost calved from December 2010 to February 
2017. Likewise, the 3-breed crossbreds and their HO herdmates calved from September 2012 to March 2017, and the HO-sired third-generation crossbreds and their HO herdmates calved from September 2014 to March 2017. All cows analyzed had an opportunity to complete 305 DIM before data collection ceased in December 2017. Observations were assigned to herdyear-seasons (HYS) of first, second, or third calving and HYS were defined as 4-mo seasons from January to April, May to August, and September to December. The seasons aligned with climatic conditions in Minnesota. Data were edited to ensure balanced numbers of observations within each lactation number and HYS, and edits were performed separately for each generation of crossbreds and their respective HO herdmates and for each lactation number. Each combination of lactation number and HYS was required to contain at least 3 crossbred and $3 \mathrm{HO}$ herdmates to remain in the data. For the analysis of 2-breed and 3-breed crossbreds and their respective $\mathrm{HO}$ herdmates, the HYS with less than 3 VR-sired or MO-sired crossbreds were combined with the next smallest contiguous HYS. A maximum of 3 HYS (12 mo) within the same herd were combined, and a minimum of 3 cows in each breed type (e.g., VR $\times$ HO crossbreds, $\mathrm{MO} \times \mathrm{HO}$ crossbreds, or their $\mathrm{HO}$ herdmates) were required. For the HO-sired crossbreds and their HO herdmates, no combination of HYS was necessary because the 2 types of HO-sired crossbreds were analyzed jointly and HYS with less than 3 cows of each breed group were discarded in the initial step of the HYS edit.

The analysis of THC and the 5 categories of health treatment cost for the 2-breed or 3-breed crossbreds and their respective $\mathrm{HO}$ herdmates included the fixed effects of lactation number (1 to 3 ), HYS nested within lactation number, breed group (crossbred or HO), breed of sire nested within breed group (e.g., $\mathrm{VR} \times \mathrm{HO}$ or $\mathrm{MO}$ $\times$ HO nested within crossbred, and henceforth referred to as breed type), interaction of lactation number and breed group, and interaction of lactation number and breed type. Also, cow nested within breed type was regarded as a random effect. The HPMIXED procedure of SAS (release 9.4, SAS Institute Inc., Cary, NC) was used to perform the ANOVA and obtain least squares solutions. The orthogonal contrasts of breed type (each type of 2-breed and 3-breed crossbred compared with their respective $\mathrm{HO}$ herdmates) were subjected to the Bonferroni correction for multiple comparisons. Within each lactation number, the HO herdmates were designated the control to correct the tests of significance for comparing each crossbred breed type with their $\mathrm{HO}$ herdmates. For analysis of THC for the HO-sired thirdgeneration crossbreds and their $\mathrm{HO}$ herdmates, the fixed effects included HYS of calving and breed group (crossbred or HO). The GLM procedure (SAS) was used to perform the ANOVA and obtain least squares solutions.

$S B$ and $G L$. Calving of cows spanned from December 2010 to December 2017 for the 3 generations analyzed for SB and GL. Twin or other multiple births $(\mathrm{n}=657)$ and calvings of cows resulting from unprescribed matings $(n=666)$ were removed. Primiparous cows were analyzed separately from multiparous cows for both SB and GL. Data were assigned to HYS of calving and edited by lactation number to ensure at least 3 crossbreds and $3 \mathrm{HO}$ herdmates were present within each combination of HYS and lactation number as described previously for the analysis of health treatment cost. However, the second and third lactations of cows were subsequently combined into a single multiparous group, and either 2 or 3 contiguous HYS were combined for the HYS with fewer than 3 primiparous or multiparous cows for a single breed type.

The analysis of SB and GL of 2-breed and 3-breed crossbreds and their respective $\mathrm{HO}$ herdmates included the fixed effects of HYS of calving, sex of calf, breed group of calf, breed type of calf, interaction of sex and breed group of calf, and interaction of sex and breed type of calf. Cow nested within breed type was a random effect for the analysis of multiparous cows. For the comparison of primiparous HO-sired (third-generation) crossbreds and their HO herdmates, the fixed effects

Table 2. Descriptions of minimum (1), intermediate (5), and maximum (9) scores for linear conformation traits

\begin{tabular}{llll}
\hline Trait $^{1}$ & 1 & 5 & 9 \\
\hline $\begin{array}{l}\text { Stature at the withers } \\
\text { Angularity }\end{array}$ & Short $(\leq 129 \mathrm{~cm})$ & Intermediate $(140 \mathrm{~cm})$ & Tall $(\geq 150 \mathrm{~cm})$ \\
Rib perpendicular to ground and & Some angle to rib and moderate & Open and angled rib and \\
Body depth & coarse & flesh neck & Deep \\
Foot angle & Shallow & Proportionate to body length & Steep $\left(\geq 65^{\circ}\right)$ \\
Udder clearance from the hock & Low $\left(\leq 25^{\circ}\right)$ & Intermediate $\left(45^{\circ}\right)$ & High $(\geq 15 \mathrm{~cm}$ above hocks $)$ \\
Rear teat width & Low $(\geq 5 \mathrm{~cm}$ below hocks $)$ & Intermediate $(5 \mathrm{~cm}$ above & Close \\
Teat length of front teats & Wide & hocks $)$ & Central \\
\hline
\end{tabular}

${ }^{1}$ All traits were subjectively scored with measurement goals provided for stature, foot angle, udder clearance, and teat length. 
included HYS of first calving, sex of calf, breed group of calf, and the interaction of sex and breed group of calf.

Because SB was a binary trait, the LOGISTIC procedure (SAS) was used to perform the ANOVA and obtain least squares solutions. For GL of primiparous cows, the GLM procedure (SAS) was used to perform the ANOVA and obtain least squares solutions. For SB and GL of multiparous cows, the ANOVA was completed and least squares solutions were estimated with the HPMIXED procedure (SAS); however, the significance tests for contrasts of least squares solutions for $\mathrm{SB}$ were attained from the HPGLIMMIX procedure of SAS. The Bonferroni adjustment was used in the same manner as for the THC to adjust contrasts for multiple comparisons of breed type and the interaction of sex of calf with breed type.

Survival. Cows sold for dairy purposes during first lactation (38 crossbreds and $33 \mathrm{HO}$ ) were removed from the data for all of the survival traits. Also, cows sold for dairy purposes during second lactation (29 crossbreds and $18 \mathrm{HO}$ ) were removed from the data for second-lactation and third-lactation survival traits and for survival to third and fourth calving. Likewise, cows sold for dairy purposes during third lactation (1 crossbred and $3 \mathrm{HO}$ ) were removed from the data for third-lactation survival traits and for survival to fourth calving.

Cows included in the analysis of calving again within 14 or $17 \mathrm{mo}$ were required to have 14 or $17 \mathrm{mo}$ of opportunity, respectively, between calving and the end of data collection (December 31, 2017). Cows included in the analysis of death loss were required to have at least 15 mo of opportunity between calving and the end of data collection. Cows included in survival to subsequent calving had at least 15 mo of opportunity to complete each lactation before the end of data collection. A very small number of first $(\mathrm{n}=5)$, second $(\mathrm{n}=3)$, and third $(\mathrm{n}=4)$ lactations of cows were longer than $15 \mathrm{mo}$ and still in progress at the end of the study, and these lactations were removed from the data because the death or survival status of the cows was unknown. Cows were assigned to HYS of calving and, subsequently, edited and combined by the same criteria used for health treatment cost to ensure adequate numbers of crossbreds and their HO herdmates were available for comparison within lactation number and HYS. For survival to subsequent calving, HYS edits were applied only to HYS of first calving because this trait was cumulative from first calving.

The analysis of percentage of cows that calved again within 14 or 17 mo was across lactations for each generation of 2-breed or 3-breed crossbreds and their respective HO herdmates. Fixed effects included lactation number, HYS of calving nested within lactation number, breed group of cow, breed type of cow, interaction of lactation number and breed group, and interaction of lactation number and breed type. Cow nested within breed type was regarded as a random effect. The GLIMMIX procedure (SAS) was used to perform the ANOVA and obtain least squares solutions, and tests of significance were adjusted with the Bonferroni correction to determine significant differences between breed types. For the analysis of first lactations of HOsired crossbreds and their HO herdmates, fixed effects included HYS of calving and breed group of cow. The LOGISTIC procedure (SAS) was used to perform the ANOVA and obtain solutions for breed groups.

Death loss and survival to subsequent calving were analyzed separately for each of the first 3 lactations of the 2-breed and 3-breed crossbreds and their respective HO herdmates, and the analysis included the fixed effects of HYS of calving, breed group of cow, and breed type of cow. The fixed effects for the analysis of HOsired crossbreds compared with their $\mathrm{HO}$ herdmates included HYS of calving and breed group of cow. The LOGISTIC procedure (SAS) was used to perform the ANOVA and obtain least squares solutions. For the multiple comparisons of breed types among 2-breed and 3 -breed crossbreds and their $\mathrm{HO}$ herdmates, tests of significance were adjusted with a Bonferroni correction.

Conformation and Body Condition. Cows analyzed for conformation traits and BCS calved from December 2010 to August 2017. Lactations of cows were assigned to HYS of calving and edited in the same manner as for health treatment cost. For 2-breed crossbreds and their HO herdmates, data for all conformation traits and BCS from the first 3 lactations were available for analysis. For 3-breed crossbreds and their HO herdmates, only the first and second lactations of cows had sufficient numbers of observations for the conformation traits after the HYS edits were applied, and only the first lactations of cows were analyzed for BCS. Lastly, conformation traits were analyzed for HOsired crossbreds and their HO herdmates during first lactation, but BCS was not.

Fixed effects for the statistical analysis of the conformation traits and BCS for 2-breed and 3-breed crossbreds compared with their respective $\mathrm{HO}$ herdmates included lactation number, HYS of calving nested within lactation number, breed group of cow, breed type of cow, interaction of lactation number and breed group of cow, interaction of lactation number and breed type of cow, and DIM on day of scoring (4 classes from 2 to 19 DIM, 20 to 39 DIM, 40 to 59 DIM, and 60 to 150 DIM) nested within lactation number. Cow nested within breed type was regarded as a random effect. The HPMIXED procedure (SAS) was used to perform the ANOVA and obtain least squares solutions. The 
orthogonal contrasts of breed types were adjusted with a Bonferroni correction as previously described. The BCS of 3-breed crossbreds and their HO herdmates contained data only from first lactation, and fixed effects for the statistical analysis included HYS of calving, breed group of cow, breed type of cow, and DIM on day of scoring. The GLM procedure (SAS) was used to perform the ANOVA and obtain least squares solutions. The Bonferroni correction was applied to the contrasts between each crossbred breed type and their HO herdmates. For analysis of the conformation traits of HO-sired crossbreds and their HO herdmates during first lactation, the fixed effects included HYS of calving, breed group of cow, and DIM on day of scoring, and the GLM procedure (SAS) was used to perform the ANOVA and obtain least squares solutions.

\section{RESULTS AND DISCUSSION}

\section{Health Treatment Cost}

Two-Breed Crossbreds and HO Herdmates. The fixed effects of lactation number, HYS nested within lactation number, and breed group of cow were significant $(P<0.01)$ for the analysis of THC and the 5 categories of health treatment cost for the 2-breed crossbreds compared with their HO herdmates, except breed group was not significant for health treatment cost of REPRO and LAME. Furthermore, breed type of cow was significant $(P<0.05)$ for THC and the interaction of lactation number, and breed group was significant $(P<0.05)$ for the treatment cost of MAST for the 2-breed crossbreds compared with their HO herdmates. The THC was lowest for cows during first lactation, as expected, and THC increased incrementally with lactation number (Table 3). During first lactation, the VR $\times$ HO crossbreds $(-16 \%)$ tended $(P=0.10)$ to have lower THC compared with their HO herdmates, but the MO $\times$ HO crossbreds $(-28 \%)$ had significantly lower $(P<$ 0.01) THC compared with their HO herdmates. The 2-breed crossbred types combined had significantly lower $(P<0.01)$ THC $(-23 \%)$ compared with their HO herdmates during first lactation. Likewise, the 2-breed crossbreds had lower $(P<0.01)$ THC compared with their HO herdmates in second $(-29 \%)$ and in third $(-21 \%)$ lactation (Table 3). Separate analysis of the 5 categories of health treatment cost indicated the difference for THC between the 2-breed crossbreds and their HO herdmates resulted from significantly lower $(P<0.01)$ health treatment cost for only 3 of the 5 categories during multiparous lactations (Table 3 ). The 2-breed crossbreds had lower health treatment cost of MAST (-18\%), META (-33\%), and MISC (-33\%) compared with their HO herdmates across the first 3 lactations.

The THC measured health treatment cost only when health treatment was provided but excluded health disorders without health treatment. This was the case

Table 3. Least squares solutions and SE for total health cost and categories of health treatment cost (US\$) for the combined 2-breed crossbreds, Viking Red $\times$ Holstein crossbreds, and Montbéliarde $\times$ Holstein crossbreds compared with their Holstein herdmates

\begin{tabular}{|c|c|c|c|c|c|c|c|c|}
\hline Trait (US\$ unless noted) & \multicolumn{2}{|c|}{ Holstein } & \multicolumn{2}{|c|}{ Both crossbred types } & \multicolumn{2}{|c|}{ Viking Red $\times$ Holstein } & \multicolumn{2}{|c|}{ Montbéliarde $\times$ Holstein } \\
\hline First lactation (n) & \multicolumn{2}{|c|}{1,280} & \multicolumn{2}{|c|}{1,216} & \multicolumn{2}{|c|}{624} & \multicolumn{2}{|c|}{592} \\
\hline Mastitis & 12 & 0.9 & 10 & 0.9 & 10 & 1.2 & 10 & 1.3 \\
\hline Reproduction & 10 & 1.2 & $7 \dagger$ & 1.3 & 9 & 1.7 & $5^{*}$ & 1.7 \\
\hline Lameness & 8 & 0.6 & 8 & 0.6 & 8 & 0.8 & 9 & 0.8 \\
\hline Second lactation (n) & \multicolumn{2}{|c|}{1,007} & \multicolumn{2}{|c|}{969} & \multicolumn{2}{|c|}{498} & \multicolumn{2}{|c|}{471} \\
\hline Total health cost & 68 & 2.8 & $48^{* *}$ & 2.7 & $48^{* *}$ & 3.6 & $47^{* *}$ & 3.7 \\
\hline Mastitis & 17 & 1.1 & $13^{* *}$ & 1.1 & 14 & 1.4 & $12^{*}$ & 1.4 \\
\hline Reproduction & 13 & 1.5 & $10^{*}$ & 1.4 & $9 \dagger$ & 1.9 & 10 & 2.0 \\
\hline Lameness & 11 & 0.7 & 10 & 0.7 & 10 & 0.9 & 10 & 0.9 \\
\hline Metabolic & 17 & 1.5 & $10^{* *}$ & 1.4 & $10^{* *}$ & 1.9 & $10^{* *}$ & 1.9 \\
\hline Miscellaneous & 9 & 0.9 & $5^{* *}$ & 0.9 & $5^{* *}$ & 1.1 & $4^{* *}$ & 1.2 \\
\hline Metabolic & 29 & 1.8 & $21^{* *}$ & 1.6 & 24 & 2.3 & $19^{* *}$ & 2.3 \\
\hline Miscellaneous & 12 & 1.1 & $9^{* *}$ & 1.0 & 9 & 1.4 & $8^{*}$ & 1.4 \\
\hline
\end{tabular}

*Significant difference $(P<0.05)$ from Holsteins. ${ }^{*}$ Significant difference $(P<0.01)$ from Holsteins. $\dagger$ Tendency for significant difference $(P<$ 0.10) from Holsteins. 
for severe health disorders without a cost-effective health treatment being applied. The 7 herds evaluated individual cows to assess whether treatment, culling, or euthanasia was optimal for the welfare of a cow and an optimal economic outcome. The THC in this study was previously studied with data only from the HO cows in this study to estimate heritability and genetic and phenotypic correlations between THC and other traits (Donnelly, 2017). In recent years, the incidence rates of producer-recorded health treatments have been studied extensively for HO cows using national data (Koeck et al., 2012; Parker Gaddis et al., 2012; Bourrigan et al., 2016). Some studies quantified health treatment using economic measures (e.g., Jones et al., 1994; Guard, 2008); however, most studies neglected to sum health treatment cost across types of health treatments.

Three-Breed Crossbreds and HO Herdmates. The fixed effects of lactation number and HYS of calving nested within lactation number were significant $(P$ $<0.01)$ for THC and the 5 categories of health treatment cost for the 3-breed crossbreds compared with their HO herdmates. Breed group was significant $(P<$ 0.01 ) for THC and the health treatment cost of MAST, META, and MISC. Furthermore, breed type was significant $(P<0.01)$ for THC and the health treatment cost of MAST for the 3-breed crossbreds compared with their HO herdmates. Also, the interaction of lactation number with breed group was significant $(P<0.05)$ for the analysis of THC and the health treatment cost of MAST, META, and MISC. Lastly, the interaction of lactation number with breed type was significant $(P$ $<0.01$ ) for the analysis of the health treatment cost of MAST for the 3-breed crossbreds compared with their HO herdmates.

The THC of all 3 breed types increased with lactation number, similar to the result of the 2-breed crossbreds; however, the magnitude of the increase with lactation number was larger for the 3 -breed crossbreds and their HO herdmates compared with the 2-breed crossbreds and their HO herdmates (Table 4). The THC was not different for 3-breed crossbreds compared with their $\mathrm{HO}$ herdmates during first lactation. However, the 3-breed crossbreds combined had significantly lower $(P<0.01)$ THC during their second $(-26 \%)$ and third $(-26 \%)$ lactations compared with their HO herdmates, and the $\mathrm{VR} \times \mathrm{MO} / \mathrm{HO}(-19 \%$ and $-17 \%)$ and $\mathrm{MO} \times \mathrm{VR} / \mathrm{HO}$ $(-33 \%$ and $-34 \%)$ crossbreds each had significantly lower $(P<0.01)$ THC during their second and third lactation, respectively (Table 4). Despite the lower numerical THC of $\mathrm{MO} \times \mathrm{VR} / \mathrm{HO}$ crossbreds compared with $\mathrm{VR} \times \mathrm{MO} / \mathrm{HO}$ crossbreds during each of the first 3 lactations, the differences between the 2 crossbred breed types were nonsignificant.

Similar to the results of the 2-breed crossbreds, the 3 -breed crossbreds and their HO herdmates significantly differed $(P<0.01)$ for only 3 of the 5 categories

Table 4. Least squares solutions and SE for total health cost and categories of health treatment cost (US\$) for the combined 3-breed crossbreds, Viking Red $\times$ Montbéliarde/Holstein crossbreds, and Montbéliarde $\times$ Viking Red/Holstein crossbreds compared with their Holstein herdmates

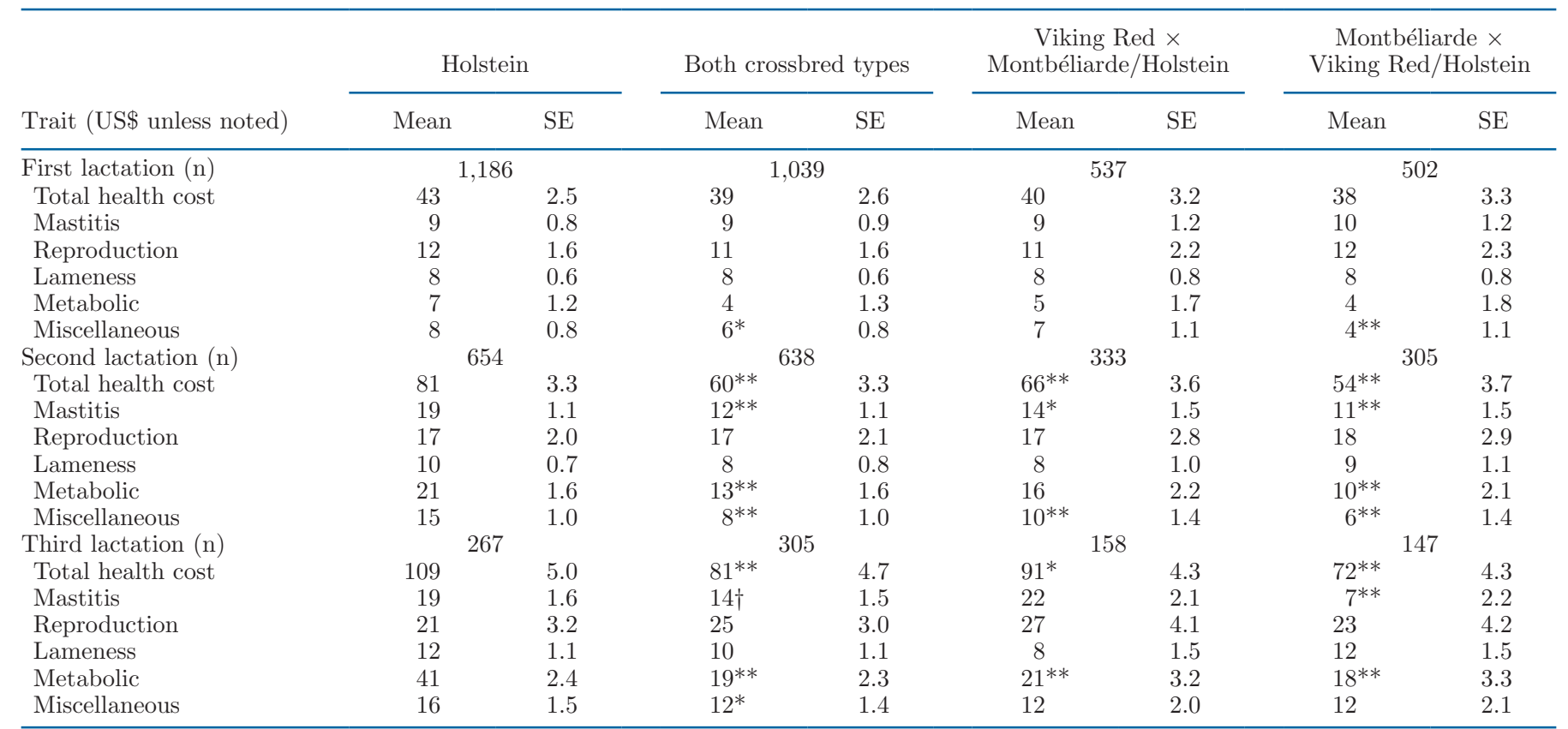

${ }^{*}$ Significant difference $(P<0.05)$ from Holsteins. ${ }^{* *}$ Significant difference $(P<0.01)$ from Holsteins. $\dagger$ Tendency for significant difference $(P<$ 0.10) from Holsteins. 
that contributed to THC. The 3-breed crossbreds had lower health treatment cost of MAST $(-20 \%)$, META $(-48 \%)$, and MISC $(-31 \%)$ compared with their HO herdmates across the first 3 lactations. These results were anticipated because VR-sired and MO-sired crossbreds usually carry more body condition compared with their HO herdmates (Hazel et al., 2017; ShonkaMartin et al., 2019), and higher BCS is beneficial for cow health (Roche et al., 2013). Furthermore, increased clinical mastitis is associated with lower reproductive performance (Oltenacu and Broom, 2010), and both the 2-breed and 3-breed crossbreds had superior fertility compared with their respective $\mathrm{HO}$ herdmates during the first 3 lactations (Hazel et al., 2020).

A reduction in the LAME cost was anticipated for the 2-breed or 3-breed crossbreds compared with their respective HO herdmates because previous studies documented cows with increased META disorders are at a higher risk for hoof disorders (Schöpke et al., 2013). Furthermore, Blöttner et al. (2011) found less incidence of hoof disorders across the first 3 lactations of Brown Swiss $\times \mathrm{HO}$ crossbreds compared with their HO herdmates in a German institutional herd. The LAME treatment cost included a broad range of LAME disorders but did not measure the precise etiology, duration, or recurrence of disorders. Perhaps, breed groups differed for LAME disorders, but potential differences were not apparent. Typically, only LAME disorders that resulted in abnormal gait were detected and LAME treatment may not have been provided to cows that were subsequently culled.

Little previous research has compared crossbreds with their $\mathrm{HO}$ herdmates for either incidence or cost of health disorders. A Swedish study by Jönsson (2015) found reciprocal crossbreds of the Swedish Red (SR) and HO breeds had lower incidence for reproductive disorders, metabolic disorders, and mastitis compared with HO cows during their first 3 lactations. In the same study, pure SR cows also had significantly lower incidence of the same 3 health disorders during all lactations compared with HO cows. Therefore, Jönsson (2015) concluded the majority of the advantage of the 2-breed SR and HO crossbreds resulted from the superior health of the SR breed compared with the HO breed. In Northern Ireland, Ferris et al. (2018) compared SR-sired crossbreds with their HO herdmates in an institutional grazing herd and reported lower incidence of mastitis and reproductive disorders for the SR-sired crossbreds, but similar incidence of metabolic and lameness disorders for the SR-sired crossbreds and their HO herdmates. Furthermore, MO-sired crossbreds in an institutional, confinement herd in Minnesota had improved uterine health (Mendonça et al., 2014) and superior innate immune response (Mendonça et al., 2013) compared with their HO herdmates. Finally, Peric et al. (2013) found significantly lower hair cortisol for crossbred heifers of the VR, MO, and HO breeds compared with their HO herdmates, and this suggested superior function of the hypothalamic-pituitary-adrenal axis (i.e., lower chronic stress levels) for the crossbred heifers compared with their HO herdmates.

HO-Sired Crossbreds and HO Herdmates. The effect of HYS of first calving was highly significant $(P<0.01)$ for the analysis of THC during first lactation for the HO-sired crossbreds compared with their HO herdmates. Fewer HO-sired crossbred $(\mathrm{n}=275)$ and their HO herdmates $(\mathrm{n}=444)$ were available for analysis compared with the 2 previous generations of first-lactation cows. This generation of crossbreds and HO herdmates commenced first calving only during the final $3 \mathrm{yr}$ of the study, and this was fewer years compared with the 2-breed and 3-breed crossbreds and their respective $\mathrm{HO}$ herdmates.

The first-lactation HO-sired crossbreds $(\$ 40 \pm 4.0)$ were not significantly different from their $\mathrm{HO}$ herdmates $(\$ 36 \pm 3.2)$ for THC during first lactation. Furthermore, none of the 5 categories of health treatment cost differed $(P<0.05)$ between the breed types during first lactation. A breed group difference for THC was less likely because the HO-sired crossbreds (mean of 5-eighths HO content) and their HO herdmates were the most similar, genetically, of the 3 generations of crossbreds in this study. Furthermore, differences in THC for crossbreds compared with their HO herdmates were small among first-lactation cows in all generations because health disorders are most prevalent among cows during the transition period of multiparous lactations (Donnelly, 2017).

Cumulative THC Within Herds for the First 3 Lactations. Results differed for THC for the 7 herds by lactation number and breed group for the 2-breed crossbreds and their HO herdmates (Figure 2). The $\mathrm{THC}$ for the 7 herds was less variable during first lactation than during second and third lactation. The sum of THC across the first 3 lactations for the 2-breed crossbreds ranged from $\$ 82$ (herd B) to $\$ 285$ (herd G), whereas the sum THC across the first 3 lactations of their HO herdmates ranged from $\$ 96$ (herd A) to $\$ 387$ (herd G). However, the 3-fold to 4-fold difference in THC between the herds with the lowest and highest THC is not necessarily a reflection of cow health in the 7 herds. Some of the herds more closely monitored cows and, consequently, detected more health disorders, and some of the herds were more aggressive in treating minor health disorders than other herds. Furthermore, some of the herds used activity monitoring systems or 


\section{2-breed crossbreds and Holstein herdmates}

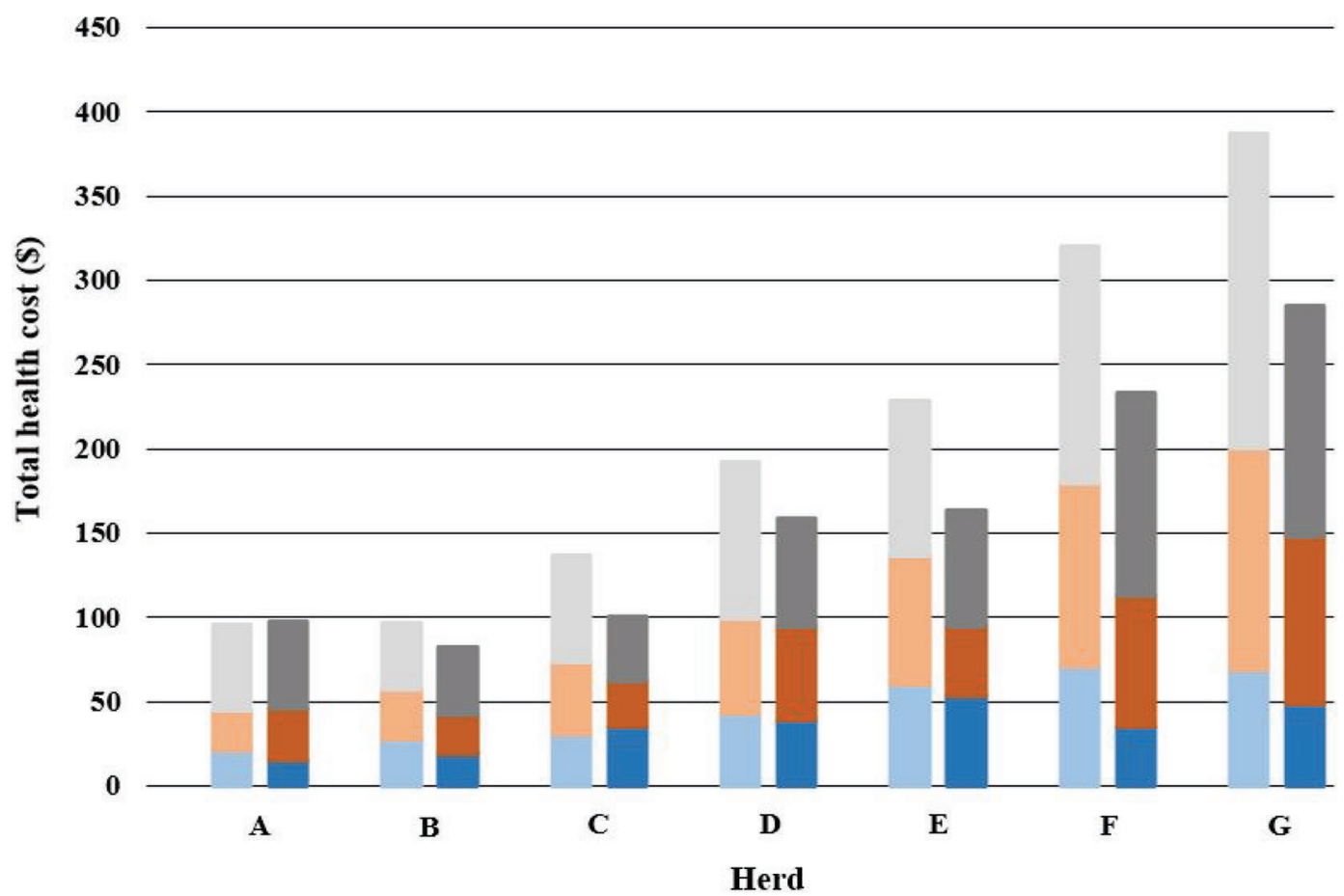

Figure 2. Cumulative least squares solutions of total health cost (US\$) for 2-breed crossbreds and their Holstein herdmates during first (Holsteins $=$ light blue bars; crossbreds $=$ dark blue bars), second (Holsteins $=$ light orange bars; crossbreds $=$ dark orange bars), and third (Holsteins $=$ light gray bars; crossbreds $=$ dark gray bars) lactation for 7 Minnesota dairy herds.

rumination monitoring systems, and these management tools may have helped detect more health disorders. Finally, some of the herds may have invested more heavily in routine preventative treatments or dietary additives to reduce health disorders. Nonetheless, each herd in the study provided equal opportunity for the detection and treatment of health disorders across breed groups, and the THC was either similar or lower for the 2-breed crossbreds compared with their HO herdmates in each lactation number for all 7 herds (Figure 2).

Similar to the results of the 2-breed crossbreds, the 3-breed crossbreds had similar or lower THC compared with their HO herdmates by lactation number in the 7 herds (Figure 3). In most cases, cumulative THC for the 2-breed crossbreds and their $\mathrm{HO}$ herdmates were similar for herds with 3-breed crossbreds and their HO herdmates. However, herd $\mathrm{C}$ had a much larger difference of THC for the 3-breed crossbreds and their $\mathrm{HO}$ herdmates (Figure 3) compared with the 2-breed crossbreds and their HO herdmates (Figure 2). For herd $\mathrm{C}$, the HO herdmates of the 3-breed crossbreds had a 3 -fold increase of REPRO cost and a 2-fold increase of META cost compared with the HO herdmates of the 2-breed crossbreds. For herd D, THC was higher for both the 3-breed crossbreds and their HO herdmates compared with the 2-breed crossbreds and their $\mathrm{HO}$ herdmates.

\section{$S B$ and $G L$}

Two-Breed Crossbreds and $\mathrm{HO}$ Herdmates. For SB of primiparous cows, the fixed effects of sex of calf and breed group of calf explained $(P<0.01)$ variation. For GL of primiparous cows, the fixed effects of HYS of calving, sex of calf, breed group of calf, breed type of calf, and the interaction of breed type of calf with sex of calf explained $(P<0.05)$ variation. The 2 -breed crossbred cows had a $-4 \%$ lower SB rate compared with their HO herdmates $(8 \%)$, and this was one-half of the SB rate at first calving (Table 5$)$. Both the $\mathrm{VR} \times \mathrm{HO}(P<$ $0.05)$ and $\mathrm{MO} \times \mathrm{HO}(P<0.01)$ crossbred cows had less SB compared with their HO herdmates. As expected, male calves had higher $(P<0.05) \mathrm{SB}$ and longer $(P<$ $0.01)$ GL than female calves for each breed type, and these results agreed with other research for pure $\mathrm{HO}$ calves (Lombard et al., 2007) and with research on sex of calf with crossbreds (Heins et al., 2006). Nonetheless, both male and female calves (3-breed crossbreds) of the 


\section{3-breed crossbreds and Holstein herdmates}

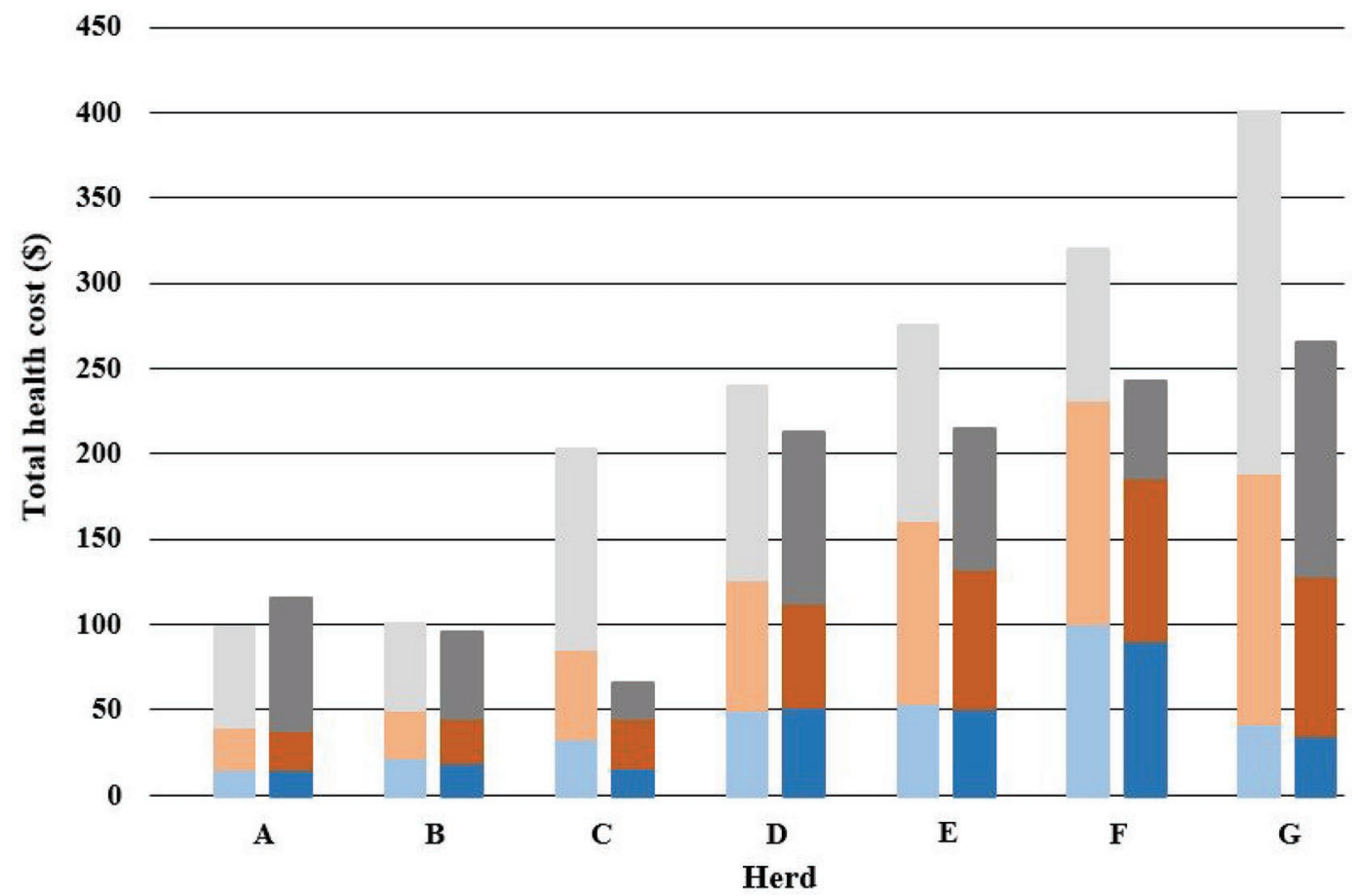

Figure 3. Cumulative least squares solutions of total health cost (US\$) for 3-breed crossbreds and their Holstein herdmates during first (Holsteins = light blue bars; crossbreds = dark blue bars), second (Holsteins = light orange bars; crossbreds = dark orange bars), and third (Holsteins $=$ light gray bars; crossbreds $=$ dark gray bars) lactation for 7 Minnesota dairy herds.

2-breed crossbreds had lower $(P<0.05)$ SB compared with their respective male and female HO herdmates for first calving. Also, the MO-sired calves from VR $\times$ HO crossbreds had $+4.4 \mathrm{~d}$ longer GL and the VR-sired calves from $\mathrm{MO} \times \mathrm{HO}$ crossbreds had $+3.3 \mathrm{~d}$ longer GL compared with their HO herdmates. The GL is pri- marily dictated by the genetics of the calf, and the $\mathrm{MO}$ breed as well as other breeds of cattle originating in the Alpine region of Europe are known for their longer GL. Ledos and Moureaux (2013) reported $+7 \mathrm{~d}$ longer GL for the MO breed in France compared with the HO breed. The MO-sired and VR-sired crossbred calves in

Table 5. Least squares solutions and SE for stillbirth rate and gestation length for the combined 2-breed crossbreds, Viking Red (VR) $\times$ Holstein $(\mathrm{HO})$ crossbreds, and Montbéliarde $(\mathrm{MO}) \times \mathrm{HO}$ crossbreds compared with their $\mathrm{HO}$ herdmates

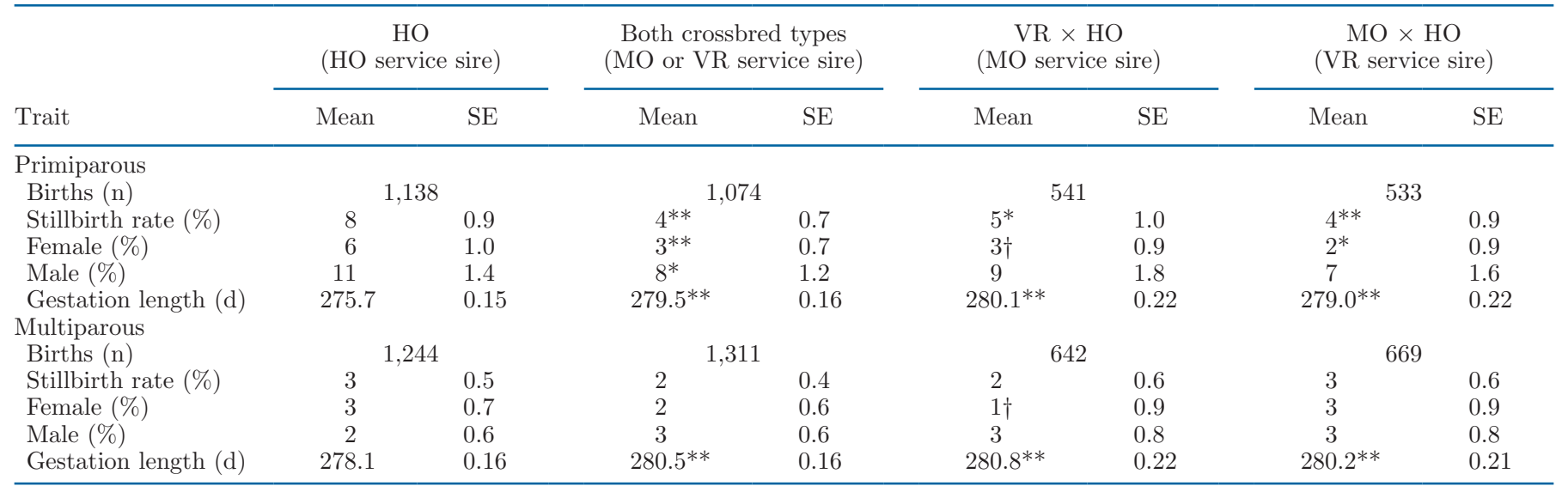

*Significant difference $(P<0.05)$ from HO. ${ }^{* *}$ Significant difference $(P<0.01)$ from HO. $\nmid$ Tendency for significant difference $(P<0.10)$ from HO. 
this study had a mean of $50 \%$ and $25 \%$ MO genetic content, respectively. Therefore, the longer GL of the $\mathrm{MO} \times \mathrm{VR} / \mathrm{HO}$ and $\mathrm{VR} \times \mathrm{MO} / \mathrm{HO}$ crossbred calves compared with their HO herdmates was expected.

For SB of the multiparous 2-breed crossbreds and their HO herdmates, none of the fixed effects significantly $(P>0.15)$ explained variation. For GL of the same multiparous cows, the fixed effects of HYS of calving, sex of calf, breed group of calf, breed type of calf, and the interaction of breed type of calf with sex of calf significantly $(P<0.05)$ explained variation and the interaction of breed group of calf and sex of calf tended $(P=0.06)$ to be significant. The SB rate was low $(2 \%$ to $3 \%$ ) for both the 2-breed crossbreds compared with their HO herdmates regardless of sex of calf (Table 5). The GL was $+2.4 \mathrm{~d}$ longer for the 3-breed crossbred calves compared with their HO herdmates, and both of the crossbred breed types had longer GL compared with their $\mathrm{HO}$ herdmates. However, the $\mathrm{MO} \times \mathrm{VR} /$ $\mathrm{HO}$ and $\mathrm{VR} \times \mathrm{MO} / \mathrm{HO}$ crossbred calves did not differ for GL, but the male calves had longer GL than female calves across the breed types.

Apparently, the longer GL of both primiparous and multiparous crossbred cows did not cause more SB of crossbred calves compared with their HO herdmates. Actually, the SB was substantially lower for the primiparous cows despite the +3.8 d longer GL. A positive relationship usually exists between higher SB and longer GL within the HO breed (López de Maturana et al., 2009). However, the crossbred calves in this study had mean HO content of only $25 \%$. Instead, the crossbred calves had mean VR content of either $25 \%$ or $50 \%$, and VR cows have substantially less SB than HO cows (Jönsson, 2015). Heins et al. (2006) reported significantly lower SB for both Scandinavian Red $\times$ $\mathrm{HO}(5.1 \%)$ and $\mathrm{MO} \times \mathrm{HO}(6.2 \%)$ crossbreds compared with their HO herdmates (14.0\%) at first calving.

Both the crossbred dams and the crossbred calves in this study may have benefited from direct or maternal heterosis for SB. However, estimation of heterosis in this study was not possible because pure VR and MO herdmates were not included in the experimental design. Sørensen et al. (2008) reported the expected direct heterosis for SB may range from $-5 \%$ to $10 \%$ and maternal heterosis for SB may range from $5 \%$ to $10 \%$ depending on the breeds used for crossbreeding.

Three-Breed Crossbreds and HO Herdmates. For SB of primiparous cows, sex of calf and breed group of calf significantly $(P<0.01)$ explained variation for the statistical analysis of 3-breed crossbreds compared with their HO herdmates. For GL of primiparous cows, the fixed effects of HYS of first calving, sex of calf, and breed type of calf significantly $(P<0.01)$ explained variation and breed group of calf and the interaction of sex of calf with breed group of calf both tended ( $P$ $<0.10)$ to explain variation. The HO-sired crossbred calves from the 3 -breed crossbred cows had a $-3 \%$ lower $(P<0.01)$ SB rate at first calving compared with their HO herdmates (Table 6). The lower SB of the crossbred calves was mostly due to the influence of the $-3 \%$ lower $\mathrm{SB}$ rate of the $\mathrm{HO}$-sired calves from $\mathrm{VR} \times$ $\mathrm{MO} / \mathrm{HO}$ crossbred dams. As expected, male calves had more SB than the female calves born to primiparous cows. The GL was significantly longer $(+0.9 \mathrm{~d})$ for the calves born to primiparous $\mathrm{MO} \times \mathrm{VR} / \mathrm{HO}$ crossbreds compared with their $\mathrm{HO}$ herdmates. All of the calves in this generation had HO sires, and therefore, smaller differences between breed groups were expected for both

Table 6. Least squares solutions and SE for stillbirth rate and gestation length for the combined 3-breed crossbreds, Viking Red $\times$ Montbéliarde/ Holstein $(\mathrm{HO})$ crossbreds, and Montbéliarde $\times$ Viking Red/HO crossbreds compared with their HO herdmates

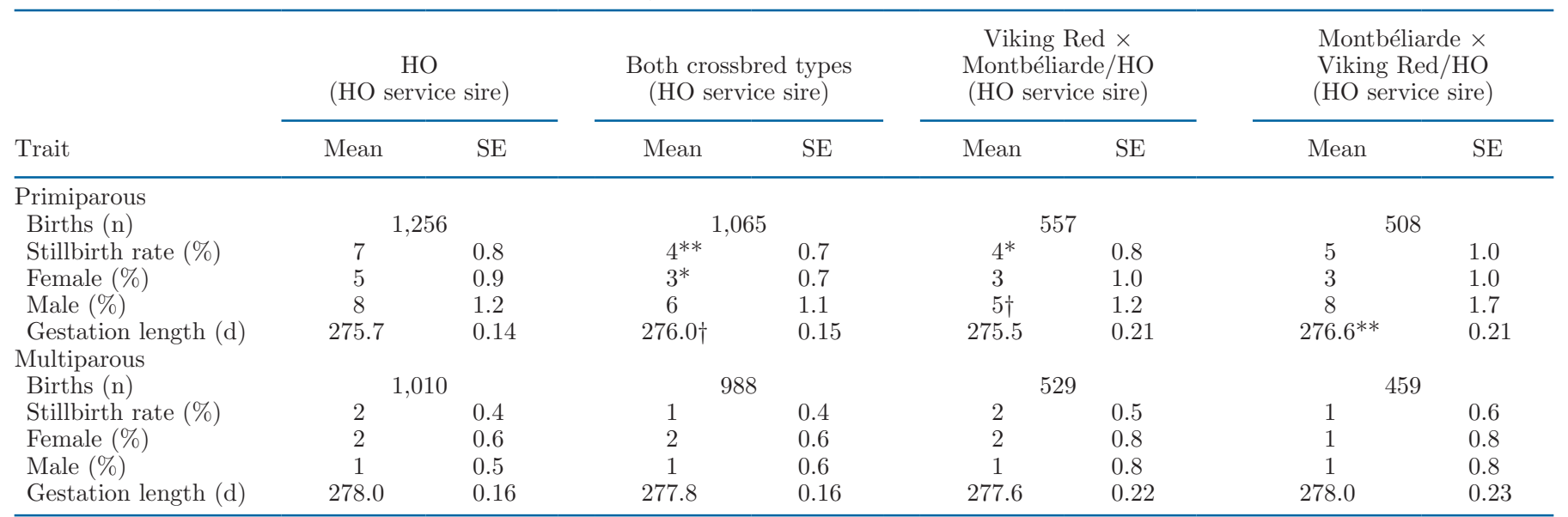

${ }^{*}$ Significant difference $(P<0.05)$ from HO. ${ }^{*}$ Significant difference $(P<0.01)$ from HO. $\nmid$ Tendency for significant difference $(P<0.10)$ from HO. 
$\mathrm{SB}$ and GL than for the 2-breed crossbreds compared with their HO herdmates.

For the SB of multiparous 3-breed crossbreds compared with their HO herdmates, none of the fixed effects significantly explained variation, and only HYS of calving and sex of calf significantly $(P<0.01)$ explained variation of GL for multiparous cows. The HO-sired calves from the multiparous 3-breed crossbreds were not different from the HO-sired calves from their $\mathrm{HO}$ herdmates for either SB or GL (Table 6).

HO-Sired Crossbreds and HO Herdmates. Sex of calf had a significant $(P<0.01)$ effect for the analysis of SB and GL for first-lactation HO-sired crossbred dams compared with their HO herdmates. Also, HYS of first calving and breed group of calf was significant $(P<0.05)$ for the analysis of GL. The SB did not differ for VR-sired and MO-sired calves born to the HO-sired primiparous crossbreds compared with $\mathrm{HO}$-sired calves born to their HO primiparous herdmates (Table 7). The GL was $+1.8 \mathrm{~d}$ longer for the crossbreds compared with their HO herdmates, and this result was anticipated because about $50 \%$ of these crossbred calves were sired by MO bulls.

The results from both the 2-breed crossbreds and the HO-sired third-generation crossbreds analyzed in this study suggest cows giving birth to MO-sired calves may experience a longer GL of approximately $3 \mathrm{~d}$. Therefore, dairy producers may wish to adjust expected calving dates accordingly.

\section{Survival}

Two-Breed Crossbreds and HO Herdmates. Lactation number, HYS of calving nested within lactation number, breed group, and breed type were significant $(P<0.05)$ fixed effects in the analysis of percentage that calved again within 14 or 17 mo for the comparison of 2-breed crossbreds with their HO herdmates. For each lactation number, a higher percentage $(P<$ 0.05 ) of the 2-breed crossbreds calved again within 14 or 17 mo compared with their HO herdmates (Table 8).
Interestingly, the difference between the breed groups increased as cows advanced from first to second and second to third lactation. The 2-breed crossbreds were $+7 \%$ compared with their HO herdmates for calved again within 14 mo for first lactation, but the 2-breed crossbreds had a larger advantage, numerically, for calved again within 14 mo during second $(+12 \%)$ and third $(+14 \%)$ lactations compared with their HO herdmates. A similar increase was observed for calved again within 17 mo because the 2-breed crossbreds were $+5 \%$, $+9 \%$, and $+12 \%$ compared with their HO herdmates during first, second, and third lactations, respectively (Table 8 ). For both survival traits, the $\mathrm{VR} \times \mathrm{HO}$ and $\mathrm{MO} \times \mathrm{HO}$ crossbreds were different $(P<0.05)$ from each other only for third lactation because the MO $\times$ HO crossbreds had a higher percentage of cows calving again within $14 \mathrm{mo}(+10 \%)$ and $17 \mathrm{mo}(+12 \%)$ compared with the VR $\times$ HO crossbreds. The percentage of cows that calved again within 14 and 17 mo reflected both the ability of cows to have a subsequent lactation and the ability of cows to calve again within a fixed interval of time. The 14- and 17-mo intervals were chosen because they reflect a calving interval of cows with moderate and poor fertility, respectively. Only a small percentage of cows in this study calved again after a 17-mo calving interval. The superior results for cows that calved again within 14 and 17 mo for 2-breed crossbreds compared with their HO herdmates likely was a reflection of significant advantages for fertility of the 2-breed crossbreds compared with their HO herdmates (Hazel et al., 2020).

The fixed effect of HYS of calving was not significant $(P>0.92)$ for the analysis of death loss in any of the first 3 lactations. Both the 2-breed crossbreds (2.9\%) and their $\mathrm{HO}$ herdmates $(3.5 \%)$ had a low rate of death loss during first lactation. The results for death loss in this study were similar to those reported by Heins et al. (2012); however, that study reported Scandinavian Red $\times \mathrm{HO}(1.6 \%)$ and $\mathrm{MO} \times \mathrm{HO}(2.0 \%)$ crossbreds had less death loss from first calving to 305 DIM compared with their HO herdmates (5.3\%). In this study, death loss

Table 7. Least squares solutions and SE for stillbirth rate and gestation length for Holstein-sired crossbreds compared with their Holstein herdmates for first calving

\begin{tabular}{|c|c|c|c|c|}
\hline \multirow[b]{2}{*}{ Trait } & \multicolumn{2}{|c|}{$\begin{array}{c}\text { Holstein } \\
\text { (Holstein service sire) }\end{array}$} & \multicolumn{2}{|c|}{$\begin{array}{l}\text { Holstein-sired crossbred } \\
\text { (Viking Red or Montbéliarde service sire) }\end{array}$} \\
\hline & Mean & $\mathrm{SE}$ & Mean & $\mathrm{SE}$ \\
\hline Births (n) & \multicolumn{2}{|c|}{560} & \multicolumn{2}{|c|}{412} \\
\hline Stillbirth rate $(\%)$ & 5 & 1.1 & 3 & 1.0 \\
\hline Female (\%) & 4 & 1.1 & 2 & 0.9 \\
\hline Male (\%) & 8 & 1.8 & 6 & 1.7 \\
\hline Gestation length (d) & 276.3 & 0.23 & $278.1^{* *}$ & 0.22 \\
\hline
\end{tabular}

**Significant difference $(P<0.01)$ from Holsteins. 
Table 8. Least squares solutions and SE for survival for the combined 2-breed crossbreds, Viking Red $\times$ Holstein crossbreds, and Montbéliarde $\times$ Holstein crossbreds compared with their Holstein herdmates

\begin{tabular}{|c|c|c|c|c|c|c|c|c|c|c|c|c|}
\hline \multirow[b]{2}{*}{ Trait (\%) } & \multicolumn{3}{|c|}{ Holstein } & \multicolumn{3}{|c|}{ Both crossbred types } & \multicolumn{3}{|c|}{ Viking Red $\times$ Holstein } & \multicolumn{3}{|c|}{ Montbéliarde $\times$ Holstein } \\
\hline & $\mathrm{n}$ & Mean & $\mathrm{SE}$ & $\mathrm{n}$ & Mean & $\mathrm{SE}$ & $\mathrm{n}$ & Mean & $\mathrm{SE}$ & $\mathrm{n}$ & Mean & $\mathrm{SE}$ \\
\hline Calved again within 14 mo & 1,250 & 63 & 1.5 & 1,190 & $70^{* *}$ & 1.5 & 608 & $69^{*}$ & 2.0 & 582 & $71^{* *}$ & 2.0 \\
\hline Calved again within 17 mo & 1,239 & 76 & 1.4 & 1,180 & $81^{* *}$ & 1.3 & 604 & $81^{*}$ & 1.7 & 576 & $82^{* *}$ & 1.7 \\
\hline Death loss & 1,223 & 3.5 & 0.6 & 1,161 & 2.9 & 0.5 & 593 & 2.7 & 0.7 & 568 & 3.3 & 0.8 \\
\hline \multicolumn{13}{|l|}{ Second lactation } \\
\hline Death loss & 959 & 7.6 & 1.0 & 934 & $4.7^{* *}$ & 0.7 & 483 & $3.7^{* *}$ & 0.8 & 451 & 5.8 & 1.1 \\
\hline \multicolumn{13}{|l|}{ Third lactation } \\
\hline Calved again within $14 \mathrm{mo}$ & 559 & 40 & 2.3 & 651 & $54^{* *}$ & 2.2 & 322 & $49^{*}$ & 3.0 & 329 & $59^{* *}$ & 2.9 \\
\hline Calved again within $17 \mathrm{mo}$ & 549 & 51 & 2.4 & 650 & $63^{* *}$ & 2.1 & 322 & 57 & 3.0 & 328 & $69^{* *}$ & 2.7 \\
\hline Death loss & 560 & 7.9 & 1.3 & 649 & 6.1 & 1.0 & 319 & 7.8 & 1.6 & 330 & 4.8 & 1.2 \\
\hline \multicolumn{13}{|l|}{ Survival to subsequent calving ${ }^{1}$} \\
\hline Survival to second calving & 1,223 & 81 & 1.3 & 1,161 & $85^{* *}$ & 1.2 & 593 & $85 \dagger$ & 1.5 & 568 & $85 \dagger$ & 1.6 \\
\hline
\end{tabular}

${ }^{1}$ Survival to subsequent calving included all cows with a first calving.

*Significant difference $(P<0.05)$ from Holsteins. ${ }^{*}$ Significant difference $(P<0.01)$ from Holsteins. $\dagger$ Tendency for significant difference $(P<$ 0.10) from Holsteins.

was $-2.9 \%$ lower $(P<0.01)$ for the 2 -breed crossbreds during second lactation compared with their HO herdmates. During third lactation, the breed groups did not differ for death loss.

Death loss of cows that survived beyond fourth or later lactation was not analyzed, but differences between breed groups for death loss may exist for cows with a long lifespan because cows exit dairy herds later in life for different reasons than earlier in life (van Pelt et al., 2015). A study of Midwest dairy herds participating in milk recording (Shahid et al., 2015) found higher mortality rates of cows during fourth $(11.0 \%)$ and fifth or greater $(13.6 \%)$ lactations compared with lower mortality rates during first to third $(3.5 \%$ to $8.5 \%)$ lactations. Therefore, an analysis of cumulative death loss across the herd life of crossbreds and their HO herdmates is warranted. Furthermore, death loss is typically one of the top 3 reasons cows leave dairy herds in the United States (Dechow and Goodling, 2008; Shahid et al., 2015), and this is a concern for dairy cow welfare.

The fixed effects of HYS of first calving and breed group of cow were highly significant $(P<0.01)$ in the statistical analyses of survival to subsequent calvings. Furthermore, breed type was highly significant $(P<0.01)$ for survival to fourth calving. The 2-breed crossbreds had superior survival to subsequent calving compared with their HO herdmates (Table 8) from first to second calving $(+4 \%)$, from first to third calving $(+9 \%)$, and from first to fourth calving $(+11 \%)$. The results from this study document improved survival for 2-breed crossbreds compared with their HO herdmates as lactation number increased, and this agrees with previous research on survival of 2-breed crossbreds compared with their HO herdmates (Heins et al., 2012; Hazel et al., 2014; Clasen et al., 2019). However, Heins et al. (2012) reported a larger magnitude of difference of $+20 \%$ and $+24 \%$ for survival to third calving and $+21 \%$ and $+26 \%$ survival to fourth calving for Scandinavian Red $\times \mathrm{HO}$ and $\mathrm{MO} \times \mathrm{HO}$ crossbreds, respectively, compared with their HO herdmates. Likewise, Clasen et al. (2019) reported $+15 \%$ survival to third calving for $\mathrm{VR} \times \mathrm{HO}$ crossbreds compared with their HO herdmates in high-production herds.

Three-Breed Crossbreds and HO Herdmates. For the analysis of percentage that calved again within 14 and 17 mo for 3-breed crossbreds and their HO herdmates, the fixed effects of lactation number, HYS nested within lactation number, breed group, and the interaction of lactation number with breed group significantly $(P<0.05)$ explained variation in the models. During first lactation, a higher percentage of the 3-breed crossbreds $(70 \%)$ calved again within 14 mo (Table 9 ) compared with their HO herdmates $(63 \%)$; however, the 3-breed crossbreds $(79 \%)$ did not differ $(P=0.17)$ from their $\mathrm{HO}$ herdmates $(76 \%)$ for percentage that calved again within 17 mo. For second lactation, the 3 -breed crossbreds were higher $(P<0.01)$ for percentage that calved again within $14 \mathrm{mo}(+18 \%)$ and $17 \mathrm{mo}$ $(+13 \%)$ compared with their HO herdmates. Likewise, the 3-breed crossbreds had higher $(P<0.01)$ percentages that calved again within $14 \mathrm{mo}(+26 \%)$ and 17 mo $(+23 \%)$ during third lactation compared with their HO herdmates (Table 9). The difference between the 3-breed crossbreds and their HO herdmates for calved 
Table 9. Least squares solutions and SE for survival for the combined 3-breed crossbreds, Viking Red $\times$ Montbéliarde/Holstein crossbreds, and Montbéliarde $\times$ Viking Red/Holstein crossbreds compared with their Holstein herdmates

\begin{tabular}{|c|c|c|c|c|c|c|c|c|c|c|c|c|}
\hline \multirow[b]{2}{*}{ Trait (\%) } & \multicolumn{3}{|c|}{ Holstein } & \multicolumn{3}{|c|}{ Both crossbred types } & \multicolumn{3}{|c|}{$\begin{array}{c}\text { Viking Red } \times \\
\text { Montbéliarde/Holstein }\end{array}$} & \multicolumn{3}{|c|}{$\begin{array}{l}\text { Montbéliarde } \times \\
\text { Viking Red/Holstein }\end{array}$} \\
\hline & $\mathrm{n}$ & Mean & $\mathrm{SE}$ & $\mathrm{n}$ & Mean & $\mathrm{SE}$ & $\mathrm{n}$ & Mean & $\mathrm{SE}$ & $\mathrm{n}$ & Mean & $\mathrm{SE}$ \\
\hline \multicolumn{13}{|l|}{ First lactation } \\
\hline Calved again within 14 mo & 1,103 & 63 & 1.6 & 980 & $70^{* *}$ & 1.6 & 506 & $72^{* *}$ & 2.1 & 474 & $69 \dagger$ & 2.3 \\
\hline Calved again within 17 mo & 1,018 & 76 & 1.5 & 922 & 79 & 1.5 & 475 & 81 & 1.9 & 447 & 77 & 2.1 \\
\hline Death loss & 1,057 & 3.6 & 0.6 & 946 & 3.2 & 0.6 & 490 & 1.9 & 0.6 & 456 & 5.3 & 1.1 \\
\hline Calved again within $17 \mathrm{mo}$ & 545 & 61 & 2.3 & 525 & $74^{* *}$ & 2.1 & 273 & $75^{* *}$ & 2.8 & 252 & $74^{* *}$ & 2.9 \\
\hline Death loss & 569 & 7.1 & 1.2 & 562 & $3.3^{* *}$ & 0.8 & 293 & $2.8^{* *}$ & 0.9 & 269 & 4.0 & 1.2 \\
\hline \multicolumn{13}{|l|}{ Third lactation } \\
\hline Calved again within $14 \mathrm{mo}$ & 202 & 37 & 3.6 & 244 & $63^{* *}$ & 3.4 & 129 & $66^{* *}$ & 4.5 & 115 & $60^{* *}$ & 4.9 \\
\hline Calved again within 17 mo & 165 & 44 & 4.2 & 194 & $67^{* *}$ & 3.7 & 97 & $69^{* *}$ & 5.1 & 97 & $65^{* *}$ & 5.3 \\
\hline Death loss & 181 & 6.3 & 1.9 & 214 & 3.7 & 1.4 & 111 & 4.5 & 2.0 & 103 & 3.1 & 1.7 \\
\hline \multicolumn{13}{|l|}{ Survival to subsequent calving ${ }^{1}$} \\
\hline
\end{tabular}

${ }^{1}$ Survival to subsequent calving included all cows with a first calving.

*Significant difference $(P<0.05)$ from Holsteins. ${ }^{*}$ Significant difference $(P<0.01)$ from Holsteins. $\dagger$ Tendency for significant difference $(P<$ 0.10) from Holsteins.

again within 14 mo during second and third lactations was greater than the difference between for the 2-breed crossbreds and their HO herdmates (Table 8). The greater survival to 14 and 17 mo for the 3 -breed crossbreds than the 2-breed crossbreds compared with their respective $\mathrm{HO}$ herdmates was mostly a consequence of the superior fertility of the 3-breed crossbreds than the 2-breed crossbreds compared with their respective $\mathrm{HO}$ herdmates (Hazel et al., 2020).

Breed type significantly $(P<0.01)$ explained variation for death loss during first lactation. During second lactation, the 3 -breed crossbreds $(3.3 \%)$ had lower $(P$ $<0.01$ ) death loss (Table 9) compared with their HO herdmates $(7.1 \%)$, and the difference was mostly a result of the significantly $(P<0.01)$ lower death loss of the $\mathrm{VR} \times \mathrm{MO} / \mathrm{HO}$ crossbreds $(2.8 \%)$ compared with their HO herdmates. During third lactation, the number of observations for the 3-breed crossbreds and their HO herdmates were small because many cows had not yet had the opportunity to complete a third lactation by the end of data collection.

For analysis of survival to second calving, HYS of first calving and breed type of cow were statistically significant $(P<0.05)$. The $\mathrm{VR} \times \mathrm{MO} / \mathrm{HO}$ crossbreds had $+4 \%$ higher survival to second calving compared with their $\mathrm{HO}$ herdmates. The 3-breed crossbreds had $+11 \%$ higher survival from first to third calving compared with their HO herdmates (Table 9), and this was higher than the result for the 2-breed crossbreds compared with their HO herdmates (Table 8). Furthermore, survival to fourth calving was significantly
$(P<0.01)$ higher $(+19 \%)$ for the 3 -breed crossbreds compared with their HO herdmates. The results of this study agree with those from a study of crossbreds in 2 institutional herds that reported increased survival to third $(+20 \%)$ and fourth $(+21 \%)$ calving for MO-sired 3 -breed crossbreds compared with their HO herdmates (Hazel et al., 2014).

HO-Sired Crossbreds and HO Herdmates. Only data from first lactations of HO-sired crossbreds and their HO herdmates were available for the analysis of survival to 14 and 17 mo, death loss, and survival to second calving. For all 4 traits, none of the fixed effects significantly explained variation in the models. The HO-sired crossbreds did not differ $(P=0.22)$ from their HO herdmates for percentage calved again within 14 mo despite the $+5 \%$ numerical advantage of the HO-sired crossbreds (Table 10). Likewise, the HO-sired crossbreds and their HO herdmates had low and similar death loss (3.0\% and 4.7\%, respectively) and did not differ for survival to second calving. The numbers of cows available for analysis for survival traits of the HOsired crossbreds and their $\mathrm{HO}$ herdmates were small and SE were large; therefore, a significant difference between breed groups was not anticipated for any of the survival traits during first lactation.

The survival of $\mathrm{HO}$ cows is a major concern for dairy producers (Weigel and Barlass, 2003) and, therefore, survival has become a focal point for crossbreeding research in recent years. Other studies have documented improved survival of crossbred cows of numerous dairy breeds compared with their HO herdmates and across 
a range of environments globally including both lowinput grazing herds as well as high-input confinement herds (Buckley et al., 2014). Substantial heterosis exists for survival of dairy cows in the range of $10 \%$ to $15 \%$ for 2-breed crossbreds and 9\% to $13 \%$ for a continuous 3-breed rotation (Sørensen, 2007) when unrelated breeds are crossed. Harris et al. (2000) studied crosses between Jersey and HO in New Zealand and reported heterosis for survival from first to fifth calving ranging from $6 \%$ to 18\%. Likewise, Jönsson (2015) reported $5 \%$ to $6 \%$ heterosis for survival to third calving among crosses of the VR and HO breeds.

\section{Conformation and Body Condition}

Two-Breed Crossbreds and HO Herdmates. Both of the 2-breed crossbreds and their HO herdmates were usually scored for the conformation traits and BCS during early lactation in the 7 herds. The mean DIM at scoring was $32 \pm 0.4 \mathrm{~d}$ during first lactation, $34 \pm 0.4 \mathrm{~d}$ during second lactation, and $35 \pm 0.8 \mathrm{~d}$ during third lactation. For all conformation traits, the fixed effects of lactation number and HYS of calving nested within lactation number were highly significant $(P<0.01)$. Furthermore, breed type was significant $(P$ $<0.01)$ for STA, ANG, FA, and UC. The interaction of lactation number with breed group was significant $(P<0.05)$ for $\mathrm{BD}, \mathrm{RTW}$, and TL and the interaction of lactation number with breed type was significant $(P$ $<0.05)$ for FA, UC, and RTW. The DIM when scored was significant for ANG (cows increased in ANG with increased DIM), BD (cows increased in BD with increased DIM), UC (multiparous cows increased in UC with increased DIM), RTW (cows decreased in RTW with increased DIM), and TL (cows increased TL with increased DIM).

The STA was measured at the withers, and the 2-breed crossbreds were -1.0 point (on a 9-point scale) shorter compared with their HO herdmates during first, second, and third lactations (Table 11), and this converted to about $2.5 \mathrm{~cm}$ less STA at the withers for the 2-breed crossbreds (Select Sires Inc.). Also, both the
$\mathrm{VR} \times \mathrm{HO}$ and the $\mathrm{MO} \times \mathrm{HO}$ crossbreds had significantly shorter STA compared with their HO herdmates during all 3 lactations. Furthermore, the VR $\times \mathrm{HO}$ crossbreds ( -0.6 to -0.8 point) were shorter for STA than the $\mathrm{MO} \times \mathrm{HO}$ crossbreds during all 3 lactations. The STA of HO cows has continued to increase with time and dairy producers have increasingly expressed concern about $\mathrm{HO}$ cows being too tall for their optimal comfort and welfare.

The 2-breed crossbreds had less ANG during first $(-2.3$ points), second ( -2.1 points $)$, and third ( -2.1 points) lactations across breed types compared with their HO herdmates and both breed types of crossbreds had less $(P<0.01)$ ANG compared with their HO herdmates (Table 11). Furthermore, the MO $\times$ HO crossbreds had less ANG compared with the VR $\times$ $\mathrm{HO}$ crossbreds during each lactation number, and this was anticipated because the MO breed has historically ignored selection for more ANG unlike the HO breed, which has historically selected for more ANG across decades.

The 2-breed crossbreds had $-0.8,-0.5$, and -0.5 point less $(P<0.01) \mathrm{BD}$ compared with their HO herdmates during first, second, and third lactation, respectively (Table 11). During first lactation, the MO $\times$ HO crossbreds had less $(P<0.01)$ BD compared with the $\mathrm{VR} \times \mathrm{HO}$ crossbreds, but no difference was detected between the breed types of 2-breed crossbreds during second and third lactation.

The FA was steeper for the 2-breed crossbreds during each of the first 3 lactations, but this was completely due to the steeper FA of the $\mathrm{MO} \times \mathrm{HO}$ crossbreds (Table 11). During first lactation, the FA of the VR $\times$ $\mathrm{HO}$ crossbreds did not differ from their HO herdmates. On the other hand, in second and third lactation, the FA was significantly $(P<0.01)$ lower for the VR $\times$ HO crossbreds compared with their HO herdmates. However, no difference for LAME treatment cost was observed in this study between the 2-breed crossbreds and their HO herdmates. Häggman and Juga (2013) reported small or insignificant phenotypic correlations between feet and leg conformation and hoof disorders

Table 10. Least squares solutions and SE for survival for Holstein-sired crossbreds compared with their Holstein herdmates during first lactation

\begin{tabular}{|c|c|c|c|c|c|c|}
\hline \multirow[b]{2}{*}{ Trait (\%) } & \multicolumn{3}{|c|}{ Holstein } & \multicolumn{3}{|c|}{ Holstein-sired crossbred } \\
\hline & $\mathrm{n}$ & Mean & $\mathrm{SE}$ & $\mathrm{n}$ & Mean & SE \\
\hline Calved again within 14 mo & 356 & 66 & 3.1 & 215 & 71 & 3.6 \\
\hline Calved again within $17 \mathrm{mo}$ & 299 & 77 & 2.7 & 182 & 79 & 3.3 \\
\hline Death loss & 327 & 4.7 & 1.3 & 195 & 3.0 & 1.2 \\
\hline Survival to second calving & 327 & 81 & 2.4 & 195 & 83 & 3.0 \\
\hline
\end{tabular}


in Finnish HO cows. Therefore, direct selection for reduced hoof disorders instead of selection for feet and leg conformation may be justified.

The 2-breed crossbreds had less $(P<0.01)$ UC during first $(-1.1$ points), second $(-1.1$ points), and third ( -0.9 point) lactation compared with their HO herdmates. The udders of both types of 2-breed crossbreds and their $\mathrm{HO}$ herdmates had less UC with increasing lactation number. However, the rate of change in UC with increasing lactation number did not differ for the 2-breed crossbreds compared with their HO herdmates. The survival was superior for the 2-breed crossbreds compared with their HO herdmates during each lactation of this study; therefore, the less UC of the 2-breed crossbreds compared with their HO herdmates apparently was not a hinderance for functional milking of the 2-breed crossbreds.
The 2-breed crossbreds had wider RTW compared with their HO herdmates during first ( -0.9 point), second ( -0.8 point), and third ( -0.9 point) lactation (Table 11), and the RTW of both breed groups of cows became closer as cows advanced from first to second lactation. An ideal RTW is 5 points, which indicates teats are placed centrally beneath the quarter (Select Sires Inc.). The HO cows had mean RTW that was much closer than ideal, whereas the 2-breed crossbreds had wider mean RTW that was closer to the ideal RTW. With time, dairy producers have observed a larger percentage of $\mathrm{HO}$ cows with touching or crossing rear teats, which is a problem for functional milking, especially with robotic milking systems.

The TL was longer $(P<0.05)$ for the 2 -breed crossbreds compared with their $\mathrm{HO}$ herdmates during first $(+0.5$ point $)$ and second $(+0.2$ point $)$ lactation and was

Table 11. Least squares solutions and SE for conformation (1-to-9 scale) and BCS (1-to-5 scale) for the combined 2-breed crossbreds, Viking Red $\times$ Holstein $(\mathrm{VR} \times \mathrm{HO})$ crossbreds, and Montbéliarde $\times$ Holstein $(\mathrm{MO} \times \mathrm{HO})$ crossbreds compared with their Holstein herdmates

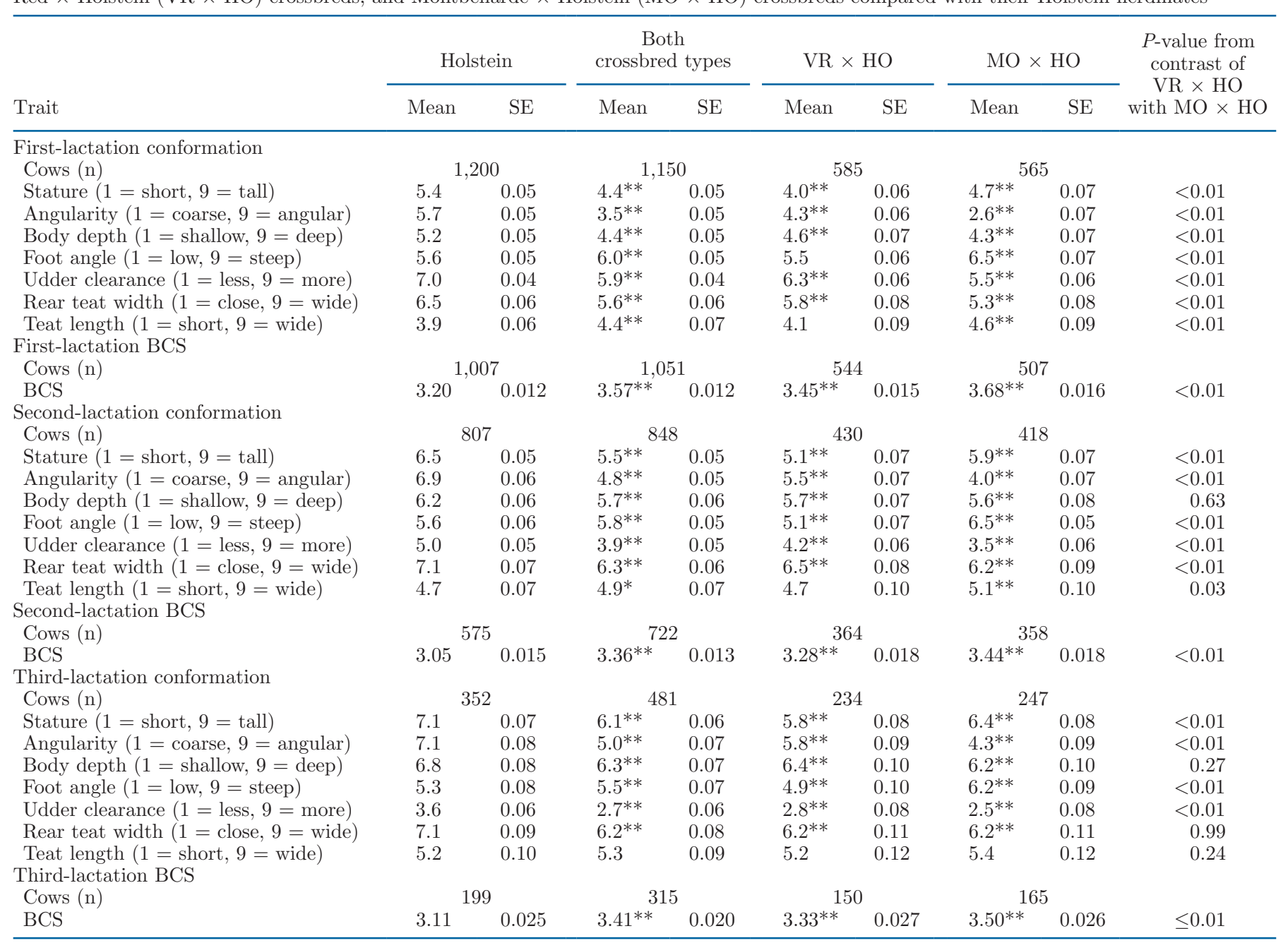

*Significant difference $(P<0.05)$ from Holsteins. ${ }^{* *}$ Significant difference $(P<0.01)$ from Holsteins. 
mostly because of the longer $\mathrm{TL}$ of the $\mathrm{MO} \times \mathrm{HO}$ crossbreds compared with both the VR $\times$ HO crossbreds and the HO herdmates (Table 11). The TL of HO cows has become shorter over time, and this has caused increased difficulty for attachment of milking units. The results from this study for RTW and TL suggest that functional milking may be an advantage for the 2-breed crossbred cows compared with their $\mathrm{HO}$ herdmates.

For BCS of 2-breed crossbreds compared with their HO herdmates, all of the fixed effects in the statistical model significantly $(P<0.05)$ explained variation. For each of the first 3 lactations, cows scored from 2 to 19 DIM had higher BCS than cows scored during the other 3 periods of early lactation. Also, the BCS of the 2-breed crossbreds was significantly higher during each of the first 3 lactations compared with their $\mathrm{HO}$ herdmates (Table 11). Furthermore, the BCS of MO $\times$ $\mathrm{HO}$ crossbreds was significantly higher compared with both the $\mathrm{VR} \times \mathrm{HO}$ crossbreds and their $\mathrm{HO}$ herdmates during each lactation number. These results agree with those of Walsh et al. (2008), who reported MO $\times \mathrm{HO}$ crossbreds (3.00) had higher BCS compared with their HO herdmates (2.77).

Three-Breed Crossbreds and HO Herdmates. The fixed effects of lactation number and HYS of calving nested within lactation number significantly $(P<$ 0.01) explained variation of each of the 7 conformation traits in the analysis of 3-breed crossbreds compared with their HO herdmates. The effect of breed type was significant $(P<0.01)$ for ANG, FA, UC, and RTW. Also, the interaction of lactation number with breed group was significant $(P<0.01)$ for $\mathrm{FA}$ and $\mathrm{UC}$ and the interaction of lactation number with breed type tended $(P<0.10)$ to explain variation for both FA and RTW. The DIM at scoring nested with lactation number explained variation for ANG (cows increased in ANG with increased DIM), BD (cows increased for BD with increased DIM), UC (multiparous cows increased in UC with increased DIM), RTW (cows decreased in RTW with increased DIM), and TL (cows increased in TL with increased DIM).

The 3-breed crossbreds had -1.3 points shorter STA, which was equivalent to about $-3.3 \mathrm{~cm}$ shorter STA, compared with their HO herdmates (Table 12). The VR-sired and MO-sired 3-breed crossbreds were not different for STA during either first or second lactation. Apparently, the proportion of the VR or MO breeds in the 3-breed crossbreds had no significant effect on STA. The 3 -breed crossbreds had significantly $(P<0.01)$ less ANG compared with their HO herdmates during both first $(-2.6$ points $)$ and second $(-2.8$ points $)$ lactation (Table 12). The MO $\times$ VR/HO 3-breed crossbreds had less ANG compared with both the VR $\times \mathrm{MO} /$
HO crossbreds and their HO herdmates, and this was not surprising because the MO breed is often used for crossbreeding because of its additional body condition and muscularity. The BD of the 3 -breed crossbreds was -1.1 points and -1.0 point shallower compared with their HO herdmates during first and second lactation, respectively. The 2 breed types of 3 -breed crossbreds did not differ from each other for BD in either first or second lactation. The taller STA and deeper BD of the HO herdmates of both the 2-breed and 3-breed crossbreds may be an explanation for their increased THC and poorer survival in this study. A long-term selection study on body size of $\mathrm{HO}$ cows reported cows resulting from selection for large body size had increased health care costs (Becker et al., 2012) and $88 \mathrm{~d}$ shorter herd life (Hansen et al., 1999) compared with cows selected for small body size.

The FA was steeper $(P<0.01)$ for the 3 -breed crossbreds compared with their HO herdmates during both lactation numbers (Table 12); however, the VR-sired crossbreds (with mean MO content of $25 \%$ ) had steeper $(P<0.01)$ FA during first lactation, and similar FA during second lactation, compared with their HO herdmates. Therefore, unlike the lower FA of the $\mathrm{VR} \times \mathrm{HO}$ 2-breed crossbreds compared with their HO herdmates, the $\mathrm{VR} \times \mathrm{MO} / \mathrm{HO}$ crossbreds had similar or steeper FA compared with their HO herdmates.

The 3-breed crossbreds had less $(P<0.01)$ UC during first $(-1.2$ points) and second $(-1.5$ points $)$ lactation compared with their HO herdmates (Table 12). This is equivalent to about 3.0 to $3.8 \mathrm{~cm}$ less UC for the 3 -breed crossbreds compared with their HO herdmates. The UC was subjectively scored relative to the hock and not to the ground. Because the 3-breed crossbred cows had shorter STA compared with their HO herdmates, the subjective scoring of UC may have been influenced by udders seeming deeper on shorter STA cows. For this reason, the Holstein Association USA (Brattleboro, VT) includes a negative weight on STA for the genetic evaluation of udder composite (http:// www.holsteinusa.com/pdf/Upcoming_Changes_aug17 .pdf). The long-term selection for cows with more UC was motivated by the strong correlation between more UC with less mastitis incidence (Carlström et al., 2016) and with lower MAST treatment cost (Donnelly, 2017). However, in this study, the 3-breed crossbreds had lower MAST cost compared with their HO herdmates despite less UC. Apparently, less UC of the 3-breed crossbreds did not result in more mastitis or more culling of cows because the 3-breed crossbreds in this study also had superior survival during second and third lactations compared with their HO herdmates. Similar to the 2-breed crossbreds, the 3-breed crossbreds had wider RTW (closer to the ideal score of 5) and longer TL 
compared with their HO herdmates during both first and second lactation (Table 12).

All fixed effects in the model for analysis of BCS during first lactation of 3-breed crossbreds compared with their HO herdmates were significant $(P<0.05)$. The BCS of cows decreased with increasing DIM. The BCS of the 3 -breed crossbreds was significantly $(P<0.01)$ higher for the 3-breed crossbreds compared with their HO herdmates during first lactation. This result agreed with Shonka-Martin et al. (2019), who found rotational crossbreds of the VR, MO, and HO breeds had +0.26 higher BCS compared with their HO herdmates during first lactation.

HO-Sired Crossbreds and HO Herdmates. During first lactation, the fixed effects of HYS of first calving explained significant $(P<0.01)$ variation of all 7 conformation traits of $\mathrm{HO}$-sired third-generation crossbreds compared with their HO herdmates. The DIM at scoring was a significant effect for ANG (cows increased in ANG with increased DIM), BD (cows increased in BD with increased DIM), UC (no clear directional trend), RTW (cows decreased in RTW with increased DIM), and TL (cows increased in TL with increased DIM).

The HO-sired crossbreds had significantly shorter $(P<0.01)$ STA compared with their HO herdmates of -0.7 point, which is the equivalent of $-1.8 \mathrm{~cm}$ for STA (Table 13). The HO-sired crossbreds also had -1.3 points less ANG compared with their HO herdmates and shallower BD. The FA was significantly steeper $(+0.3$ point) for the HO-sired crossbreds compared with their HO herdmates (Table 13). The udder traits followed a similar pattern to those of the previous generations because the HO-sired third-generation crossbreds had -0.6 point less $(P<0.01) \mathrm{UC},-0.5$ point more $(P<$ $0.01)$ RTW, and a tendency $(P=0.06)$ for longer TL compared with their HO herdmates (Table 13). With a mean of five-eighths $\mathrm{HO}$ content, the HO-sired crossbreds were expected to have less difference compared with their HO herdmates than the differences found for 2-breed and 3-breed crossbreds compared with their respective $\mathrm{HO}$ herdmates.

\section{Implications for the Industry}

The monetary nature of THC is a unique feature of this study, and THC has not been considered in other research on crossbreeding nor in most research on the health of dairy cows. The costs of veterinary care, pharmaceuticals, and farm labor are difficult to assign to specific health disorders of individual cows, and therefore, THC is often considered a fixed, overhead cost. Furthermore, recording of health treatments for individual cows is often variable, incomplete, or nonexistent for many dairy herds. For example, the United States has not established or enforced uniform standards for

Table 12. Least squares solutions and SE for conformation (1-to-9 scale) and BCS (1-to-5 scale) for the combined 3-breed crossbreds, Viking Red $\times$ Montbéliarde/Holstein $(\mathrm{VR} \times \mathrm{MO} / \mathrm{HO})$ crossbreds, and Montbéliarde $\times$ Viking Red/Holstein $(\mathrm{MO} \times \mathrm{VR} / \mathrm{HO})$ crossbreds compared with their Holstein herdmates

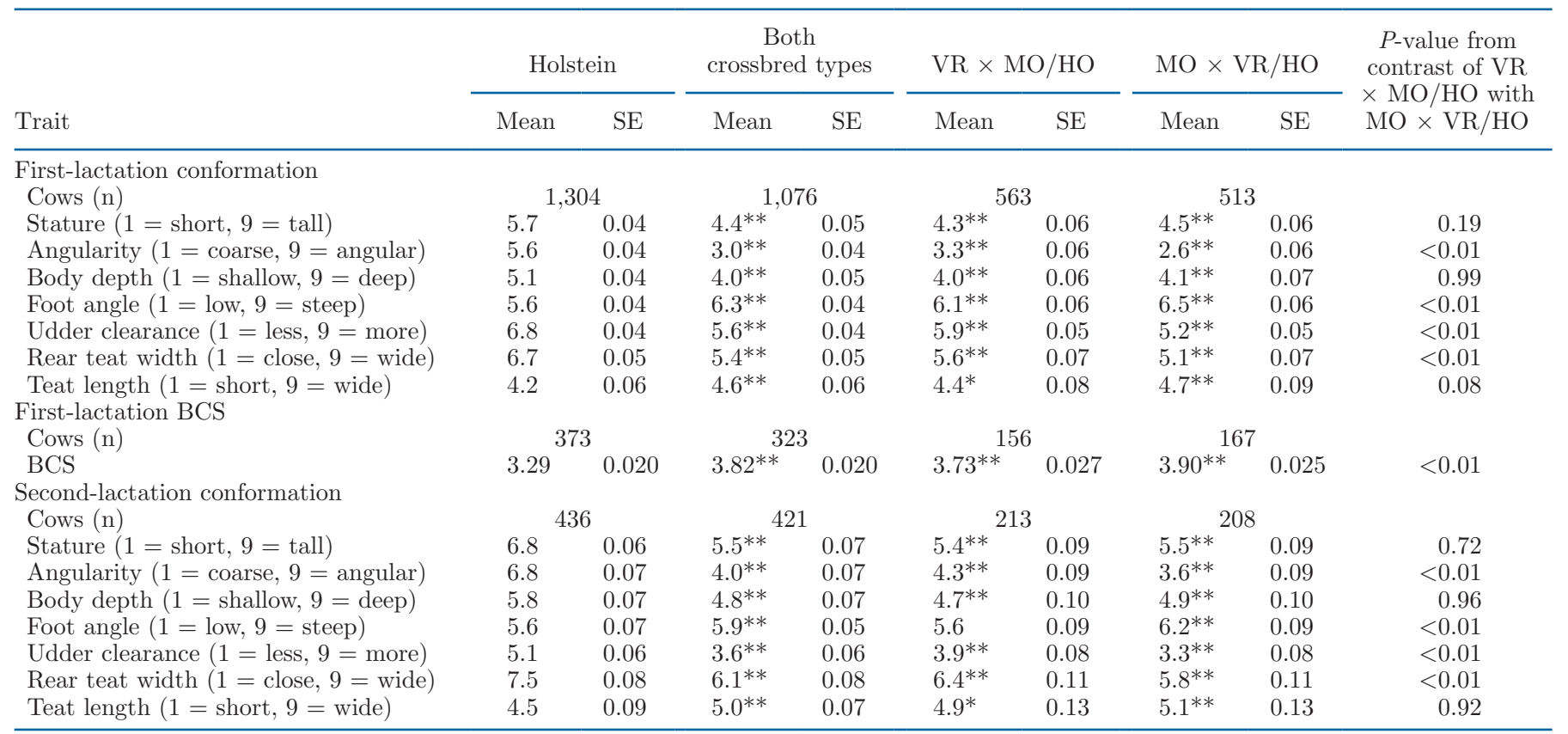

${ }^{*}$ Significant difference $(P<0.05)$ from Holsteins. ${ }^{* *}$ Significant difference $(P<0.01)$ from Holsteins. 
Table 13. Least squares solutions and SE for conformation (1-to-9 scale) for Holstein-sired crossbreds compared with their Holstein herdmates during first lactation

\begin{tabular}{|c|c|c|c|c|}
\hline \multirow[b]{2}{*}{ Trait } & \multicolumn{2}{|c|}{ Holstein } & \multicolumn{2}{|c|}{ Holstein-sired crossbreds } \\
\hline & Mean & $\mathrm{SE}$ & Mean & $\mathrm{SE}$ \\
\hline Cows (n) & \multicolumn{2}{|c|}{657} & \multicolumn{2}{|c|}{460} \\
\hline Stature $(1=$ short, $9=$ tall $)$ & 6.0 & 0.06 & $5.3^{* *}$ & 0.07 \\
\hline Angularity $(1=$ coarse, $9=$ angular $)$ & 5.5 & 0.06 & $4.2^{* *}$ & 0.07 \\
\hline Body depth $(1=$ shallow, $9=$ deep $)$ & 5.1 & 0.06 & $4.8^{* *}$ & 0.07 \\
\hline Foot angle $(1=$ low, $9=$ steep $)$ & 5.4 & 0.05 & $5.7^{* *}$ & 0.06 \\
\hline Udder clearance $(1=$ less, $9=$ more $)$ & 6.7 & 0.05 & $6.1^{* *}$ & 0.06 \\
\hline Rear teat width $(1=$ close, $9=$ wide $)$ & 6.8 & 0.06 & $6.3^{* *}$ & 0.08 \\
\hline Teat length $(1=$ short, $9=$ wide $)$ & 4.2 & 0.08 & $4.4 \dagger$ & 0.09 \\
\hline
\end{tabular}

**Significant difference $(P<0.01)$ from Holsteins. †Significant difference $(P<0.10)$ from Holsteins.

recording of health treatments. The summation of THC in this study across all 16 types of health treatments facilitated a robust distribution of THC for cows, and this would not have been the case if health observations had been recorded only in a binary fashion.

For a hypothetical herd of 500 cows (200 first, 150 second, and 150 third and later lactation) with a 12-mo calving interval, the lower THC of the 2-breed crossbreds compared with their HO herdmates in this study would result in $\$ 7,850$ more profit annually. For the same hypothetical herd of 500 cows, the lower THC of the 3-breed crossbreds compared with their HO herdmates would result in $\$ 8,150$ more profit annually.

VanRaden et al. (2018) reported that each percentage decrease in SB rate had a monetary worth of $\$ 3$ per calving. Therefore, for a hypothetical herd of 500 cows, the lower SB rate of the crossbreds in this study compared with their $\mathrm{HO}$ herdmates would result in $\$ 4,350$ more profit annually for the 2-breed crossbreds and $\$ 3,600$ for the 3 -breed crossbreds.

Sørensen et al. (2008) reviewed a large, controlled crossbreeding experiment and reported 3-breed rotational crossbreds had substantial heterosis for total merit because of their longer herd life compared with their HO herdmates. Heins et al. (2012) reported the Scandinavian Red $\times \mathrm{HO}$ and $\mathrm{MO} \times \mathrm{HO}$ crossbreds had longer herd life, which resulted in less mean replacement cost of $-\$ 0.45$ daily compared with their HO herdmates.

Globally, dairy producers have increasing awareness that the profitability of dairying is influenced by THC, the percentage of calves born alive, and the survival of cows in addition to high production $(\mathrm{kg})$. Previously reported results (Hazel et al., 2020) from this large field study of the first 3 generations of rotational crossbreeding with the VR, MO, and $\mathrm{HO}$ breeds documented the cows in this study were competitive for fat plus protein production $(\mathrm{kg})$. However, the crossbreds in this study had major advantages compared with their HO herd- mates for THC, SB, and survival. Although heterosis could not be estimated in this study, the crossbred cows likely had the benefit of heterosis on top of the additive genetic effects of the breeds.

\section{ACKNOWLEDGMENTS}

We express gratitude to the dairy producers, managers, and employees of the 7 dairies for their participation in this study and for providing data on the cows in their herds. We also thank Minnesota Select Sires Co-op Inc. for its contributions of mating individual heifers and cows with AI bulls and scoring of the conformation traits. Finally, we thank M. R. Donnelly (University of Minnesota, St. Paul) for provision of the health treatment costs. Funding for this study was provided by Coopex Montbéliarde (Roulans, France), Viking Genetics (Randers, Denmark), Creative Genetics of California (Oakdale, CA), Select Sires Inc. (Plain City, OH), and Minnesota Select Sires Co-op Inc. (St. Cloud, MN). The authors have not stated any conflicts of interest.

\section{REFERENCES}

Balandraud, N., C. Mosnier, L. Delaby, F. Dubief, J. Goron, B. Martin, D. Pomiès, and A. Cassard. 2018. Holstein ou Montbéliarde: des differences phénotypiques aux consequences économiques à l'échelle de l'exploitation. INRA Prod. Anim. 31:337-352. https:// doi.org/10.20870/productions-animales.2018.31.4.2394.

Becker, J. C., B. J. Heins, and L. B. Hansen. 2012. Costs for health care of Holstein cows selected for large versus small body size. J. Dairy Sci. 95:5384-5392. https://doi.org/10.3168/jds.2012-5344.

Blöttner, S., B. J. Heins, M. Wensch-Dorendorf, L. B. Hansen, and H. H. Swalve. 2011. Brown Swiss $\times$ Holstein crossbreds compared with pure Holsteins for calving traits, body weight, backfat thickness, fertility, and body measurements. J. Dairy Sci. 94:1058-1068. https://doi.org/10.3168/jds.2010-3305.

Bourrigan, X., S. Mattalia, C. Bouissel, R. Dremaux, M. Dupres, J. J. Evard, X. Gouraud, M. Legay, L. Maurin, B. Schmitt, J. M. Gautier, P. Roussel, and G. Blériot. 2016. French health recording systems: Possible new valorizations of events recorded by farmers. Pages 177-182 in Proc. 40th ICAR Biennial session, Puerto Varas, Chile. ICAR, Rome, Italy. 
Buckley, F., N. Lopez-Villalobos, and B. J. Heins. 2014. Crossbreeding: implications for dairy cow fertility and survival. Animal 8(s1):122-133. https://doi.org/10.1017/S1751731114000901.

Carlström, C., E. Strandberg, K. Johansson, G. Pettersson, H. Stålhammar, and J. Philipsson. 2016. Genetic associations of in-line recorded milkability traits and udder conformation with udder health. Acta Agric. Scand. A Anim. Sci. 66:84-91. https://doi.org/ 10.1080/09064702.2016.1260154.

Cartwright, S. L., L. R. Schaeffer, E. B. Burnside, and B. A. Mallard. 2012. Adaptive immune response, survival, and somatic cell score between postpartum Holstein and Norwegian Red $\times$ Holstein firstcalf heifers. J. Anim. Sci. 90:2970-2978. https://doi.org/10.2527/ jas.2011-4233.

Clasen, J. B., A. Fogh, and M. Kargo. 2019. Differences between performance of $F_{1}$ crossbreds and Holsteins at different production levels. J. Dairy Sci. 102:436-441. https://doi.org/10.3168/jds.2018 -14975 .

Colleau, J. J., and D. Regaldo. 2001. Setting up the breeding goal of French dairy breeds. Renc. Rech. Ruminants 8:329-332.

Dechow, C. D., and R. C. Goodling. 2008. Mortality, culling by sixty days in milk, and production profiles in high- and low-survival Pennsylvania herds. J. Dairy Sci. 91:4630-4639. https://doi.org/ 10.3168/jds.2008-1337.

Dechow, C. D., and L. B. Hansen. 2017. Capitalizing on breed differences and heterosis. Pages 369-378 in Large Dairy Herd Management. 3rd ed. D. K. Beede, ed. American Dairy Science Association, Champaign, IL.

Dickerson, G. E., and L. N. Hazel. 1944. Effectiveness of selection on progeny performance as a supplement to earlier culling in livestock. J. Agric. Res. 69:459-476.

Donnelly, M. R. 2017. Genetic control of health treatment costs for Holsteins in 8 high-performance herds. MS Thesis. Department of Animal Science, University of Minnesota, St. Paul.

Doublet, A.-C., P. Croiseau, S. Fritz, A. Michenet, C. Hozé, C. Danchin-Burge, D. Laloë, and G. Restoux. 2019. The impact of genomic selection on the genetic diversity and genetic gain in three French dairy cattle breeds. Genet. Sel. Evol. 51:52. https://doi .org/10.1186/s12711-019-0495-1.

Egger-Danner, C., J. B. Cole, J. E. Pryce, N. Gengler, B. Heringstad, A. Bradley, and K. F. Stock. 2015. Invited review: Overview of new traits and phenotyping strategies in dairy cattle with a focus on functional traits. Animal 9:191-207. https://doi.org/10.1017/ S1751731114002614.

Falconer, D. S., and T. F. C. Mackay. 1996. Introduction to Quantitative Genetics. 4th ed. Longman House, Harlow, Essex, UK.

Ferguson, J. D., D. T. Galligan, and N. Thomsen. 1994. Principal descriptors of body condition score in Holstein cows. J. Dairy Sci. 77:2695-2703. https://doi.org/10.3168/jds.S0022-0302(94)77212 $-\mathrm{X}$.

Ferris, C. P., P. J. Purcell, A. W. Gordon, T. Larsen, and M. Vestergaard. 2018. Performance of Holstein and Swedish-Red $\times$ Jersey/ Holstein crossbred dairy cows within low- and medium-concentrate grassland-based systems. J. Dairy Sci. 101:7258-7273. https: //doi.org/10.3168/jds.2017-14107.

Funk, D. A. 2006. Major advances in globalization and consolidation of the artificial insemination industry. J. Dairy Sci. 89:1362-1368. https://doi.org/10.3168/jds.S0022-0302(06)72203-2.

Guard, C. 2008. The costs of common diseases of dairy cattle (Proceedings). Accessed Jan. 2, 2020. http://veterinarycalendar.dvm360 .com/costs-common-diseases-dairy-cattle-proceedings- 0 .

Häggman, J., and J. Juga. 2013. Genetic parameters for hoof disorders and feet and leg conformation traits in Finnish Holstein cows. J. Dairy Sci. 96:3319-3325. https://doi.org/10.3168/jds.2012-6334.

Hansen, L. B., J. B. Cole, G. D. Marx, and A. J. Seykora. 1999. Productive life and reasons for disposal of Holstein cows selected for large versus small body size. J. Dairy Sci. 82:795-801. https://doi .org/10.3168/jds.S0022-0302(99)75298-7.

Harris, B. L., A. M. Winkelman, and L. J. Burton. 2000. Comparisons of fertility measures in strains of Holstein-Frisian cows, Jersey cows and their crosses. Pages $71-78$ in Proc. Massey Dairy Farmer's Conference. Massey University, Palmerston North, New Zealand.
Hazel, A. R., B. J. Heins, and L. B. Hansen. 2017. Fertility, survival, and conformation of Montbéliarde $\times$ Holstein and Viking Red $\times$ Holstein crossbred cows compared with pure Holstein cows during first lactation in 8 commercial dairy herds. J. Dairy Sci. 100:94479458. https://doi.org/10.3168/jds.2017-12824.

Hazel, A. R., B. J. Heins, and L. B. Hansen. 2020. Fertility and 305day production of Viking Red-, Montbeliarde-, and Holstein-sired crossbred cows compared with Holstein cows during their first 3 lactations in Minnesota dairy herds. J. Dairy Sci. 103:8683-8697. https://doi.org/10.3168/jds.2020-18196.

Hazel, A. R. B. J. Heins, A. J. Seykora, and L. B. Hansen. 2014. Production, fertility, survival, and body measurements of Montbéliarde-sired crossbreds compared with pure Holsteins during their first 5 lactations. J. Dairy Sci. 97:2512-2525. https://doi.org/10 $.3168 /$ jds.2013-7063.

Heins, B. J., L. B. Hansen, and A. De Vries. 2012. Survival, lifetime production, and profitability of Normande $\times$ Holstein, Montbéliarde $\times$ Holstein, and Scandinavian Red $\times$ Holstein crossbreds versus pure Holsteins. J. Dairy Sci. 95:1011-1021. https://doi.org/ $10.3168 /$ jds.2011-4525.

Heins, B. J., L. B. Hansen, and A. J. Seykora. 2006. Calving difficulty and stillbirths of pure Holsteins versus crossbreds of Holstein with Normande, Montbeliarde, and Scandinavian Red. J. Dairy Sci. 89:2805-2810. https://doi.org/10.3168/jds.S0022-0302(06)72357 $-8$.

Jones, W. P., L. B. Hansen, and H. Chester-Jones. 1994. Response of health care to selection for milk yield of dairy cattle. J. Dairy Sci. 77:3137-3152. https://doi.org/10.3168/jds.S0022-0302(94)77257 $-\mathrm{X}$

Jönsson, R. 2015. Estimation of heterosis and performance of crossbred Swedish dairy cows. MS Thesis. Department of Animal Breeding and Genetics, Swedish University of Agricultural Sciences, Uppsala.

Koeck, A., S. Loker, F. Miglior, D. F. Kelton, J. Jamrozik, and F. S. Schenkel. 2014. Genetic relationships of clinical mastitis, cystic ovaries, and lameness with milk yield and somatic cell score in first-lactation Canadian Holsteins. J. Dairy Sci. 97:5806-5813. https://doi.org/10.3168/jds.2013-7785.

Koeck, A., F. Miglior, D. F. Kelton, and F. S. Schenkel. 2012. Health recording in Canadian Holsteins: Data and genetic parameters. J. Dairy Sci. 95:4099-4108. https://doi.org/10.3168/jds.2011-5127.

Ledos, H., and S. Moureaux. 2013. Durée de gestation pour les principales races de l'espéce bovine: Moyenne et variabilité. Accessed Jan. 2, 2020. http://idele.fr/?eID=cmis_ download\&oID=workspace:/ /SpacesStore/6e1935c2-3970-4fb3-9320-30f29165866e.

Lombard, J. E., F. B. Garry, S. M. Tomlinson, and L. P. Garber. 2007. Impacts of dystocia on health and survival of dairy calves. J. Dairy Sci. 90:1751-1760. https://doi.org/10.3168/jds.2006-295.

López de Maturana, E., X.-L. Wu, D. Gianola, K. A. Weigel, and G. J M. Rosa. 2009. Exploring biological relationships between calving traits in primiparous cattle with a Bayesian recursive model. Genetics 181:277-287. https://doi.org/10.1534/genetics.108.094888.

Mendonça, L. G. D., C. C. Abade, E. M. da Silva, N. B. Litherland, L. B. Hansen, W. P. Hansen, and R. C. Chebel. 2014. Comparison of peripartum metabolic status and postpartum health of Holstein and Montbéliarde-sired crossbred dairy cows. J. Dairy Sci. 97:805818. https://doi.org/10.3168/jds.2013-7159.

Mendonça, L. G. D., N. B. Litherland, M. C. Lucy, D. H. Keisler, M. A. Ballou, L. B. Hansen, and R. C. Chebel. 2013. Comparison of innate immune responses and somatotropic axis components of Holstein and Montbéliarde-sired crossbred dairy cows during the transition period. J. Dairy Sci. 96:3588-3598. https://doi.org/10 $.3168 /$ jds.2012-5804.

Miglior, F., A. Fleming, F. Malchiodi, L. F. Brito, P. Martin, and C. F. Baes. 2017. A 100-year review: Identification and genetic selection of economically important traits in dairy cattle. J. Dairy Sci. 100:10251-10271. https://doi.org/10.3168/jds.2017-12968.

Oltenacu, P. A., and D. M. Broom. 2010. The impact of genetic selection for increased milk yield on the welfare of dairy cows. Anim. Welf. 19(Suppl. 1):39-49. 
Parker Gaddis, K. L. 2014. Improvement of dairy cattle health through the utilization of producer-recorded data and genomic methods. PhD Diss. Department of Animal Science and Poultry Science, North Carolina State University, Raleigh.

Parker Gaddis, K. L., J. B. Cole, J. S. Clay, and C. Maltecca. 2012. Incidence validation and relationship analysis of producer-recorded health event data from on-farm computer systems in the United States. J. Dairy Sci. 95:5422-5435. https://doi.org/10.3168/jds 2012-5572.

Peric, T., A. Comin, M. Corazzin, M. Montillo, A. Cappa, G. Campanile, and A. Prandi. 2013. Short communication: Hair cortisol concentrations in Holstein-Friesian and crossbreed $\mathrm{F}_{1}$ heifers. J. Dairy Sci. 96:3023-3027. https://doi.org/10.3168/jds.2012-6151.

Rauw, W. M., and L. Gomez-Raya. 2015. Genotype by environment interaction and breeding for robustness in livestock. Front. Genet. 6:310-325. https://doi.org/10.3389/fgene.2015.00310.

Roche, J. R., J. K. Kay, N. C. Friggens, J. L. Loor, and D. P. Berry. 2013. Assessing and managing body condition score for the prevention of metabolic disease in dairy cows. Vet. Clin. North Am. Food Anim. Pract. 29:323-336. https://doi.org/10.1016/j.cvfa.2013.03 .003.

Schöpke, K., S. Weidling, R. Pijl, and H. H. Swalve. 2013. Relationships between bovine hoof disorders, body condition traits, and test-day yields. J. Dairy Sci. 96:679-689. https://doi.org/10.3168/ jds.2012-5728.

Shahid, M. Q., J. K. Reneau, H. Chester-Jones, R. C. Chebel, and M. I. Endres. 2015. Cow- and herd-level risk factors for on-farm mortality in Midwest US dairy herds. J. Dairy Sci. 98:4401-4413. https://doi.org/10.3168/jds.2014-8513.

Shonka-Martin, B. N., B. J. Heins, and L. B. Hansen. 2019. Threebreed rotational crossbreds of Montbéliarde, Viking Red, and Holstein compared with Holstein cows for feed efficiency, income over feed cost, and residual feed intake. J. Dairy Sci. 102:3661-3673. https://doi.org/10.3168/jds.2018-15682.
Sørensen, M. K. 2007. Crossbreeding-An important part of sustainable breeding in dairy cattle and possibilities for implementation. Pages 29-40 in Crossbreeding of Dairy Cattle: The Science and the Impact. 4th Biennial W. E. Petersen Symposium, St. Paul, MN. Department of Animal Science, University of Minnesota, St. Paul. Sørensen, M. K., E. Norberg, J. Pedersen, and L. G. Christensen. 2008 Invited review: Crossbreeding in dairy cattle: A Danish perspective. J. Dairy Sci. 91:4116-4128. https://doi.org/10.3168/jds.2008 $-1273$.

van Pelt, M. L., T. H. E. Meuwissen, G. de Jong, and R. F. Veerkamp. 2015. Genetic analysis of longevity in Dutch dairy cattle using random regression. J. Dairy Sci. 98:4117-4130. https://doi.org/10 .3168/jds.2014-9090.

VanRaden, P. M., J. B. Cole, and K. L. Parker Gaddis. 2018. AIP Research Report NM\$7: Net merit as a measure of lifetime profit: 2018 revision. Accessed Oct. 21, 2019. http://aipl.arsusda.gov/ reference/nmcalc-2018.htm.

Walsh, S., F. Buckley, K. Pierce, N. Byrne, J. Patton, and P. Dillon. 2008. Effects of breed and feeding system on milk production, body weight, body condition score, reproductive performance, and postpartum ovarian function. J. Dairy Sci. 91:4401-4413. https:// doi.org/10.3168/jds.2007-0818.

Weigel, K. A., and K. A. Barlass. 2003. Results of a producer survey regarding crossbreeding on US dairy farms. J. Dairy Sci. 86:41484154. https://doi.org/10.3168/jds.S0022-0302(03)74029-6.

\section{ORCIDS}

A. R. Hazel $\odot$ https://orcid.org/0000-0002-1713-7834

B. J. Heins ๑ https://orcid.org/0000-0003-2186-9082

L. B. Hansen ๑ https://orcid.org/0000-0002-2752-2736 